\title{
Mariner 9 Observations of the South Polar Cap of Mars: Evidence for Residual $\mathrm{CO}_{2}$ Frost
}

\author{
D. A. Paige \\ Department of Earth and Space Sciences, University of California, Los Angeles \\ K. E. Herkenhoff and B. C. Murray \\ Division of Geological and Planetary Sciences, California Institute of Technology, Pasadena
}

\begin{abstract}
The first spacecraft observations of the south residual polar cap of Mars were obtained by the Mariner 9 orbiter during the Martian southern summer season, 1971-1972. Analyses of Viking orbiter observations obtained 3 Mars years later have shown that residual carbon dioxide frost was present at the south polar cap in 1977. In this study, Mariner 9 infrared interferometer spectrometer spectra and television camera images are used in conjunction with multispectral thermal emission models to constrain the temperatures of dark bare ground and bright frost regions within the south residual cap. The results provide strong evidence that carbon dioxide frost was present throughout the summer season despite the fact that the residual frost deposits observed by Mariner 9 were less extensive than those observed by Viking.
\end{abstract}

\section{INTRODUCTION}

Determining the nature of the Martian residual polar caps is fundamental to understanding the Mars climate system. Leighton and Murray [1966] proposed that the observed partial pressure of $\mathrm{CO}_{2}$ at the surface of Mars is regulated by permanent solid $\mathrm{CO}_{2}$ deposits at the poles. If permanent $\mathrm{CO}_{2}$ frost deposits exist, then the vapor pressures of these deposits determine the mass of the Martian atmosphere. Whether permanent $\mathrm{CO}_{2}$ frost deposits can exist on Mars depends on the annual polar heat balance and the total available mass of $\mathrm{CO}_{2}$ in the cap-atmosphere system. When permanent $\mathrm{CO}_{2}$ frost deposits are present, the mass of the Martian atmosphere is extremely sensitive to changes in polar radiative properties and changes in polar isolation caused by quasi-periodic variations in Mars' orbital and axial elements [Ward et al., 1974; Toon et al., 1980].

Spacecraft observations have revealed much about the nature of the Martian polar caps, but the question of whether a substantial, permanent reservoir of solid $\mathrm{CO}_{2}$ presently exists on the planet remains unanswered. This paper presents a detailed analysis of previously unanalyzed Mariner 9 infrared interferometer spectrometer (IRIS) observations combined with television imaging experiment observations of the south polar cap of Mars. The results provide strong evidence for the presence of $\mathrm{CO}_{2}$ frost at the south residual polar cap throughout the southern summer season during the 1971-1972 apparition. This conclusion has important implications for the role that the south residual polar cap may play in determining the present Martian climate.

The Mariner 9 orbiter obtained the first spacecraft observations of the Martian residual polar caps. IRIS observations of the south polar cap obtained during midsummer $\left(L_{s}=\right.$ $300^{\circ}$ ) were interpreted by Hanel et al. [1972a] to be consistent with the presence of $\mathrm{CO}_{2}$ frost. This analysis was not carried forward to observations obtained at the end of the

Copyright 1990 by the American Geophysical Union.

Paper number 89JB01428.

0148-0227/90/89JB-01428\$05.00 summer season when the residual deposits were exposed. Wide-angle and narrow-angle Mariner 9 television camera images of the south residual cap obtained near the end of the summer season were interpreted by Murray et al. [1972] to be inconsistent with the presence of substantial $\mathrm{CO}_{2}$ frost because of the highly irregular and variegated appearance of the frost deposits at all observable spatial scales down to a minimum of about $150 \mathrm{~m}$. Murray and Malin [1973] further speculated that a permanent $\mathrm{CO}_{2}$ deposit was instead located at the north polar cap, which might be favored by virtue of its somewhat lower altitude (and, therefore, somewhat higher equilibrium $\mathrm{CO}_{2}$ sublimation temperature). Furthermore, the Mariner 9 images showed the north residual cap to have thicker and more homogeneous frost deposits, which they felt were more consistent with the expected appearance of a major solid $\mathrm{CO}_{2}$ reservoir.

The Viking orbiter observations of the residual polar caps in 1976 and 1977 gave unexpected results. Infrared thermal mapper (IRTM) and Mars atmospheric water detector (MAWD) observations during northern summer proved that the north residual cap was composed of water ice and not $\mathrm{CO}_{2}$ frost [Kieffer et al., 1976a; Farmer et al., 1976]. The surface temperature of the north residual cap rose to $205 \mathrm{~K}$, which is far in excess of $\sim 150 \mathrm{~K}$, the maximum possible temperature of $\mathrm{CO}_{2}$ frost in solid-vapor equilibrium with $\mathrm{CO}_{2}$ gas in the Martian atmosphere. However, the IRTM observations of the south residual cap indicated that despite its irregular appearance, its surface temperatures did not rise during the summer season. In his analysis, Kieffer [1979] concluded that solid $\mathrm{CO}_{2}$ remained on the surface of the south residual cap throughout the summer season. This conclusion was confirmed by measurements of the polar heat balance from IRTM observations [Paige and Ingersoll, 1985].

There are two pieces of evidence that suggest that the south polar cap behavior observed by Viking in 1977 may not have been typical. Comparisons of Viking orbiter images of the retreating south seasonal polar cap with those obtained 3 Martian years earlier by Mariner 9 show that the Viking cap 


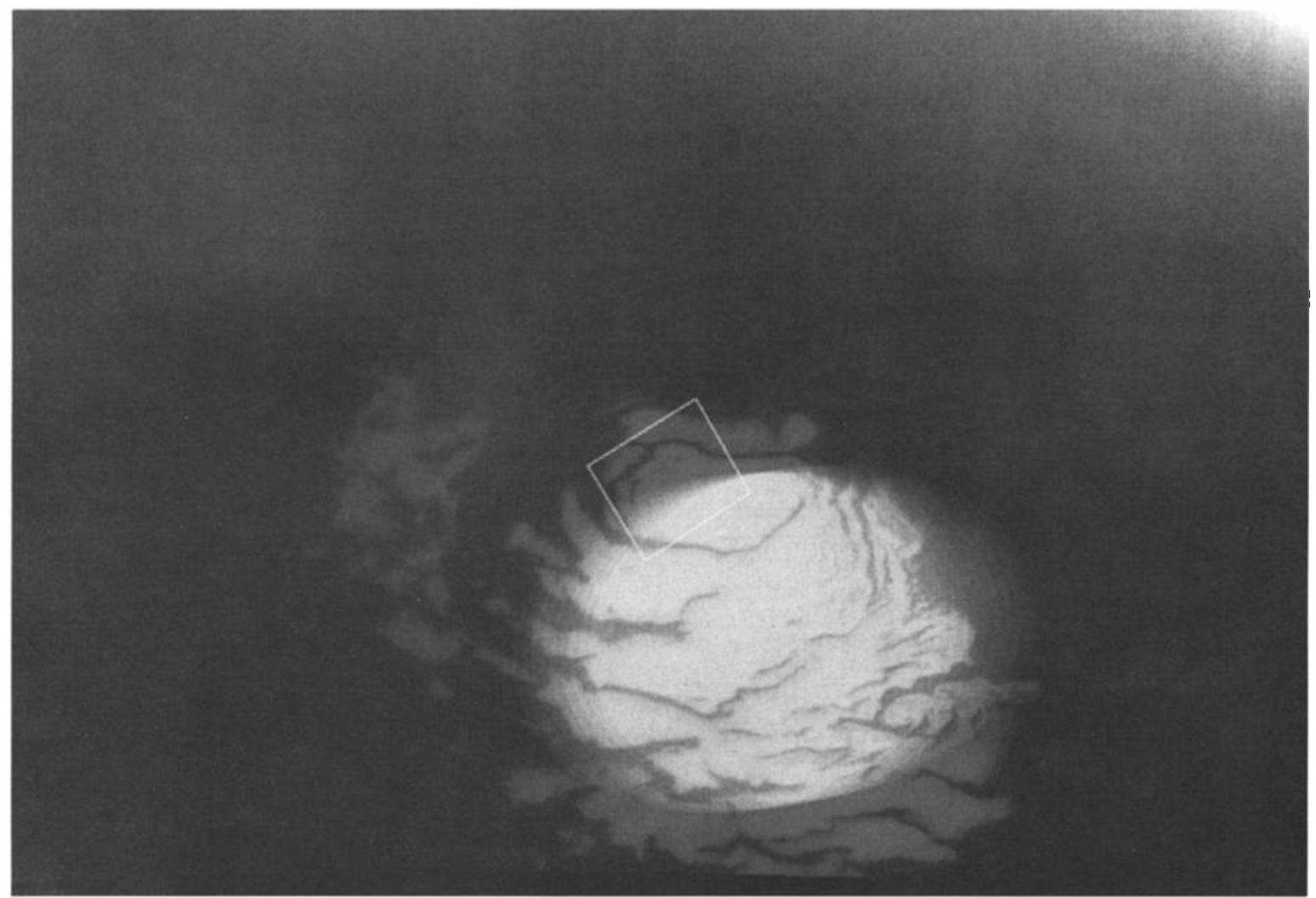

Fig. 1. Mariner 9 wide-angle television camera image of the south polar cap of Mars obtained on orbit $28\left(L_{s}=301^{\circ}\right)$. The highlighted region on the cap is the area sampled by a Mariner 9 IRIS spectrum obtained on the same orbit.

receded to the same point approximately 17 days later than the Mariner 9 cap [James et al., 1979]. The residual cap observed at the end of the summer season by Viking exhibited greater frost coverage than did the residual cap observed in Mariner 9. Also, telescopic observations have been reported to show that the atmosphere of Mars contained significantly more water vapor during the late summer season of 1969 than during the years of Viking observations [Jakosky and Barker, 1984]. Jakosky and Barker have interpreted these observations as evidence that the $\mathrm{CO}_{2}$ frost at the south residual cap is completely sublimated during certain years and that the bulk of the bright deposits at the south residual cap are composed of water ice.

Currently, the available observations point to the conclusion that the total mass of permanent, solid $\mathrm{CO}_{2}$ at the south residual cap is not sufficient to control the mass of the Martian atmosphere over climatic time scales. Fanale and Cannon [1979] have estimated that if the cap was uniformly covered with a 400 -m-thick layer of $\mathrm{CO}_{2}$ frost, it could contain at most the equivalent of 1 present Martian atmospheric mass of solid $\mathrm{CO}_{2}$. If a residual water ice cap was exposed in 1969 [Jakosky and Barker, 1984], then the reservoir of permanent $\mathrm{CO}_{2}$ at the south residual cap is probably of negligible importance.

The absence of a permanent $\mathrm{CO}_{2}$ reservoir at the south residual cap would have two important alternative implications. Either there is no large reservoir of condensed $\mathrm{CO}_{2}$ in contact with the Martian atmosphere, and the excellent agreement between the observed surface pressure on Mars and the expected surface pressure based on estimates of the annual polar heat balance [Leighton and Murray, 1966] and direct observations of the annual polar heat balance [Paige and Ingersoll, 1985] is a coincidence; or the Martian atmosphere is presently buffered by an alternate unobserved $\mathrm{CO}_{2}$ reservoir, and the permanent cap reservoir is maintained at near zero mass by an as yet undefined process. Viking lander observations of the isotopic composition of nitrogen and oxygen in the Martian atmosphere have been used to deduce that there is, presently, a very large reservoir of oxygen in contact with the atmosphere [McElroy et al., 1976]. Fanale et al. [1982] have proposed that the oxygen is in the form of $\mathrm{CO}_{2}$ adsorbed in the Martian regolith. When permanent solid $\mathrm{CO}_{2}$ deposits are not present, the mass of the Martian atmosphere could be controlled by the $\mathrm{CO}_{2}$ vapor pressure of the regolith. Alternatively, Pollack [1979] and Kahn [1985] have proposed that carbonates, formed during periods when liquid water is stable on Mars, could also be a significant oxygen reservoir for the Martian atmosphere.

In this study we analyze Mariner 9 south polar cap observations obtained during the summer season 1971-1972. Mariner 9 arrived at Mars during southern summer in 1971, when the south polar cap was approaching its residual configuration. Figure 1 shows a wide-angle image of the south polar cap obtained on orbit $28\left(L_{s}=301^{\circ}\right)$. Highresolution images like the one shown in Figure 2 indicate that frost cover at the core of the residual cap was still fairly uniform at this time, which is consistent with the presence of $\mathrm{CO}_{2}$ frost.

By orbit $116\left(L_{s}=326^{\circ}\right)$ the seasonal frost outliers seen in earlier images had vanished, and frost cover within the central portion of the residual cap became patchy. During orbit 116 the cap appeared smaller than it ever appeared 


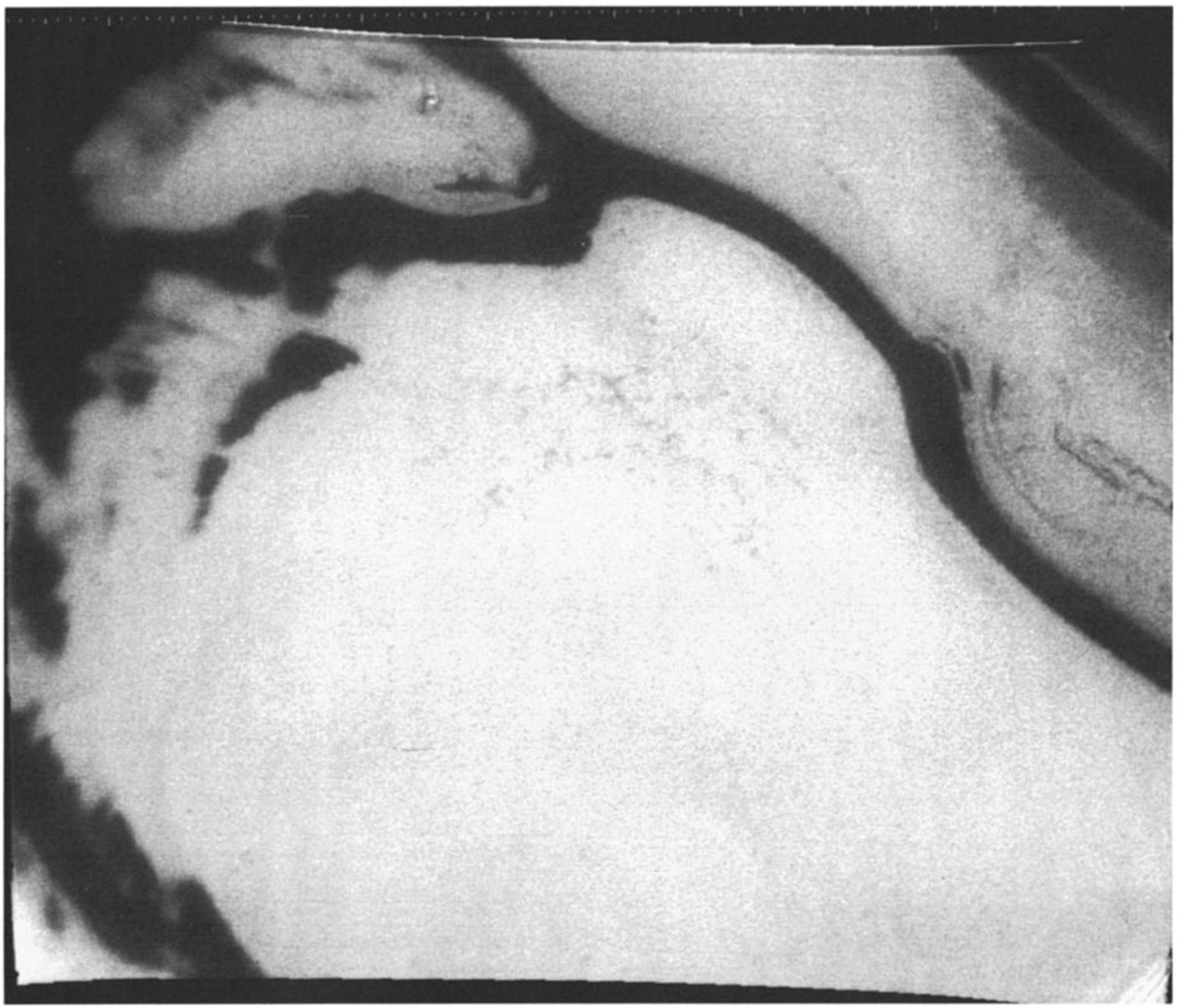

Fig. 2. Mariner 9 narrow-angle television camera image of the portion of the south polar cap of Mars obtained on orbit 28 . The region sampled is outlined in Figure 1 . At this season the cap was nearly uniformly covered with seasonal $\mathrm{CO}_{2}$ frost.

when observed by Viking in 1977. Figure 3 shows a wideangle image of the south residual cap obtained on orbit 116, and Figure 4 shows a high-resolution image of a central portion of the cap obtained during the same orbit.

We now present the IRIS and imaging data sets and describe our data reduction and analysis procedures.

\section{MARINER 9 IRIS ObSERVATIONS}

The Mariner 9 IRIS was a Michelson interferometer that measured thermal emission between 5 and $50 \mu$ with a spectral resolution of $1.2 \mathrm{~cm}^{-1}$. The instrument's field of view was circular, with a diameter of $4.5^{\circ}$ of arc. At a periapsis height of $1400 \mathrm{~km}$ this corresponded to a 110$\mathrm{km}$-diameter area for nadir viewing. The sensitivity of the instrument to radiation from outside its nominal field of view was negligible. Calibration was accomplished by viewing deep space and an on-board warm blackbody. The integration period for each spectrum was $21 \mathrm{~s}$. The Mariner 9 IRIS instrument is described in detail by Hanel et al. [1972b].

The Mariner 9 IRIS reduced data records were obtained from the National Space Sciences Data Center. The data set consists of 21,167 calibrated spectra, with associated geometry and ephemeris information Hanel et al. [1973]. Geom- etry listings for the complete data base were searched, and spectra that included the south residual cap area were extracted from the main data base and examined. Spectra with favorable south polar viewing geometry were obtained during many orbits during the sauthern summer season $\left(L_{s}\right.$ $=300^{\circ}-360^{\circ}$ ). The most suitable spectra for this study were obtained on orbits $28,58,116$, and 188.

The IRIS Reduced Data Records contain IRIS footprints and associated geometry information for each spectrum at the midpoints of the 21-s integration periods. The locations of the IRIS footprints throughout the integration periods were determined by interpolating geometric information from adjacent spectra. This procedure was only valid if there were no time gaps between adjacent spectra and the scan platform was not in motion. These conditions were only satisfied for three spectra from orbit 28 , two spectra from orbit 58, three spectra from orbit 116, and two spectra from orbit 188. Maps showing the footprints at the midpoints of these spectra are presented in Figure 5. Geometry and ephemeris data at the midpoints of these spectra are presented in Table 1.

Figure 6 shows the Mariner 9 IRIS spectra selected for this study. Measured brightness temperatures are plotted as a 


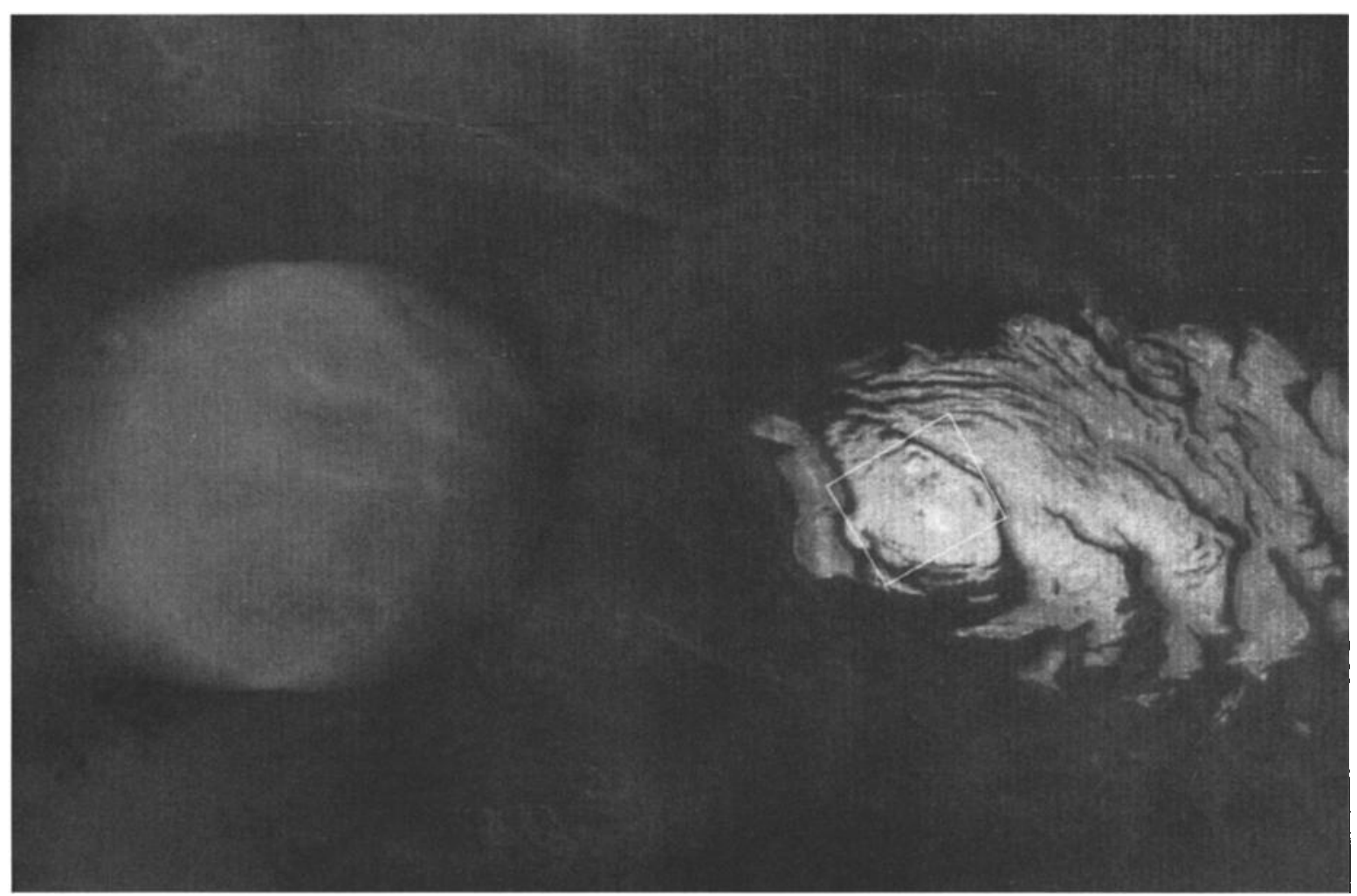

Fig. 3. Mariner 9 wide-angle television camera image of the south polar cap of Mars obtained on orbit $116\left(L_{s}=326^{\circ}\right)$. The highlighted region off the cap is the area sampled by a Mariner 9 IRIS spectrum obtained on the same orbit.

function of wavelength from 7.5 to $45 \mu$. The quality of the brightness temperature spectra is highest at the peak of the Planck function near $15 \mu$. Data obtained at the spectral extremes were discarded because of lower signal-to-noise ratios.

The spectra of bare ground regions differ markedly from the spectra that include parts of the south polar cap. Spectra that do not include the cap show relatively featureless blackbody emission except near the strong $15-\mu$ band of gaseous $\mathrm{CO}_{2}$. Spectra that do contain the south polar cap show a more complex spectral structure because of (1) the simultaneous presence of bright cold and dark warm emitting surfaces within the IRIS field of view, (2) the presence of warm emitting dust in the atmosphere overlying a colder surface, and (3) possible variations in the spectral emissivity of the surface. In this study we are primarily concerned with using the spectra to define the infrared emission from the surface.

The infrared emission from the surface is best determined in spectral "windows" where the Martian atmosphere is most transparent. The locations of these window regions are most apparent during orbit 28 , when the dust opacity of the Martian atmosphere and the temperature contrast between surface and atmosphere were the highest observed. These spectra show broad dust emission features centered at 9 and $22 \mu$; a strong gaseous $\mathrm{CO}_{2}$ emission feature centered at 15 $\mu$; and weaker water vapor rotational lines which are seen most easily at 33,36 , and $39 \mu$ (see Figure 7 ). Emission features at 11 and $12 \mu$ associated with the presence of water ice clouds [Curran et al., 1973] are not apparent in the south polar spectra. For defining the surface emission, we have chosen wavelengths of 12 and $34 \mu$ as atmospheric windows.
We assume that the measured IRIS brightness temperatures at these wavelengths are equal to the surface emission.

The accuracy of the IRIS observations at 12 and $34 \mu$ for defining the polar surface emission is determined by the absolute calibration of the IRIS instrument and the degree to which the surface emission at these wavelengths is contaminated by the polar atmosphere. Experience with the IRIS observations has shown its absolute calibration to be excellent [Hanel et al., 1973]. The question of atmospheric opacity can be dealt with by considering the observed spectral behavior near the window wavelengths.

Carbon dioxide gas and water vapor bands are relatively easy to identify in the spectra because the positions and shapes of these features can be predicted. IRIS mid-latitude spectra obtained under dust-free conditions show no discernible gas absorption at $12 \mu$. Furthermore, detailed calculations of Mars gas absorbances for nadir paths show transmission values in excess of $99 \%$ at $12 \mu$ (D. Crisp, submitted to Journal of Geophysical Research, 1989). At 34 $\mu$, gas absorption again appears to be unimportant. Line by line calculations for water vapor absorption under Martian conditions assuming $10 \mu$ of precipitable water [Conrath et al., 1973] show a region with no significant opacity at $34 \mu$ between the strong line centers at 33 and $34.5 \mu$.

The possibility that the chosen window wavelengths possess significant aerosol opacity can also be discounted to a large degree. The distinct minima in observed brightness temperatures observed at $\lambda=12 \mu$ in all the south polar cap spectra are most easily explained by sharply decreasing dust opacities at shorter wavelengths superposed on sharply increasing $\mathrm{CO}_{2}$ gas opacities at longer wavelengths. The fact that the positions of these minima stay constant in the 


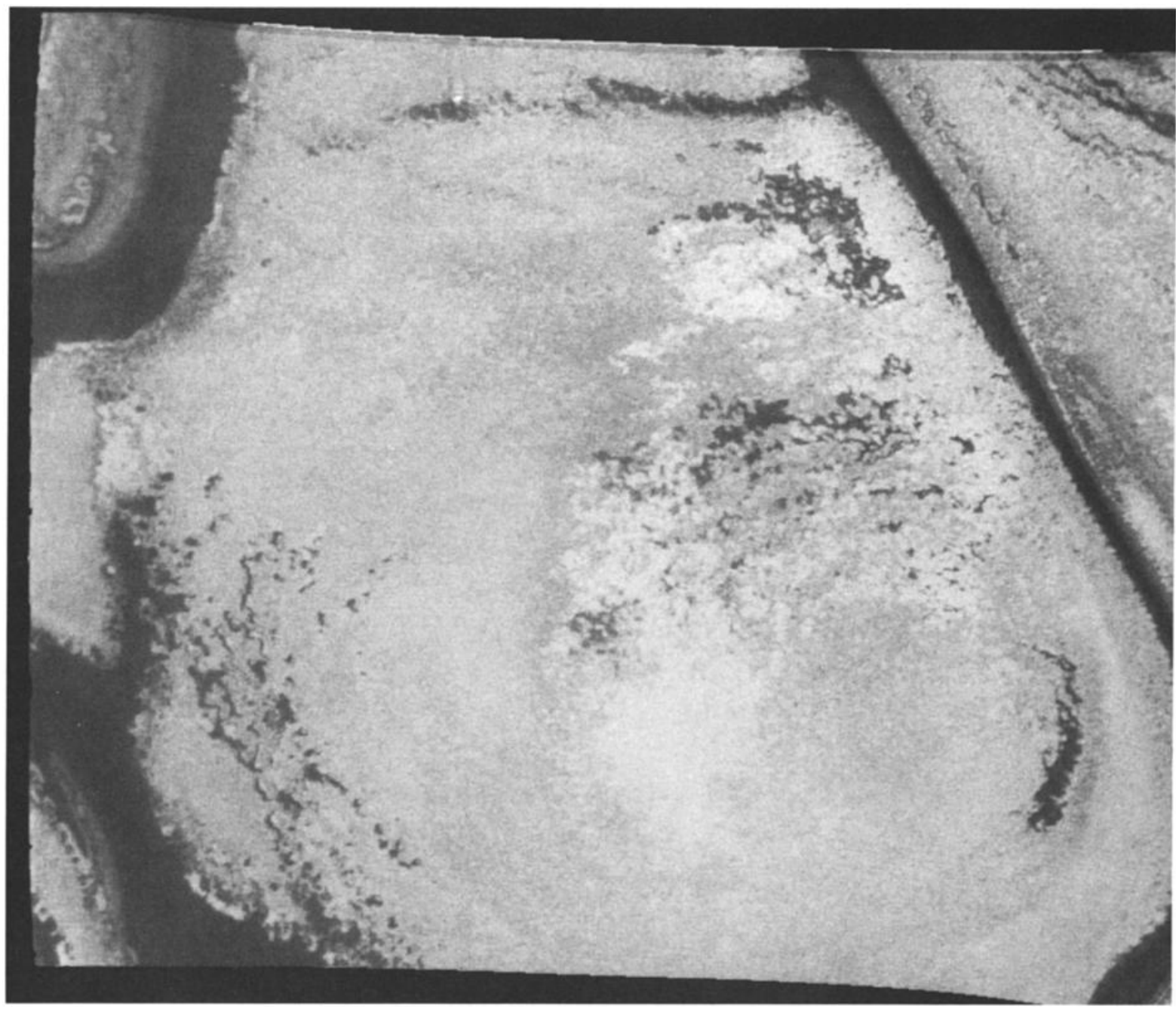

Fig. 4. Mariner 9 narrow-angle television camera image of the portion of the south polar cap of Mars obtained on orbit 116. The region sampled is outlined in Figure 3. At this season, residual frost deposits were exposed, showing an uneven, variegated texture.

spectra shown in Figure 6 despite changes in dust opacity, atmospheric temperature, and IRIS footprint location points strongly to the conclusion that both gas and aerosol opacities must be low at $12 \mu$. The unambiguous visibility of the water vapor rotational lines and of the relative flatness of the brightness temperature spectra beyond $30 \mu$ is good evidence for the absence of significant aerosol opacity beyond $30 \mu$ in the IRIS south polar spectra.

The above arguments indicate that the measured IRIS brightness temperatures at 12 and $34 \mu$ are good measures of the surface emission at these wavelengths. It is also important to point out that since the polar atmosphere is generally warmer than the surface of the south polar cap, the net systematic effect of using the brightness temperatures at the top of the atmosphere as measures of surface emission will be to overestimate the actual surface emission. Since solid carbon dioxide must be present if measured brightness temperatures are lower than $\sim 150 \mathrm{~K}$, overestimating the surface emission tends to make them more difficult to identify.

\section{Mariner 9 Television ObServations}

The Mariner 9 television subsystem consisted of two vidicon cameras: the wide-angle (A) camera, equipped with various filters, and the narrow-angle (B) camera [Cutts, 1974]. The cameras were bore-sighted on the scan platform along with the IRIS, the ultraviolet spectrometer, and the infrared radiometer. Wide-angle camera images are used for comparison with the IRIS data because their fields of view are large enough to include entire IRIS footprints. Some of the camera pointing information from the Supplementary Experimental Data Record (SEDR) used in processing the images in this study is presented in Table 2.

The selected images were corrected for shading, linearized, and filtered to remove bit errors and reseaux using calibration software now available from the U.S. Geological Survey in Flagstaff, Arizona. Residual image correction was also performed on the orbit 116 image. Derived reflectances from images that were not corrected for residual image effects are approximately $5 \%$ too high. Geometric distortion, 

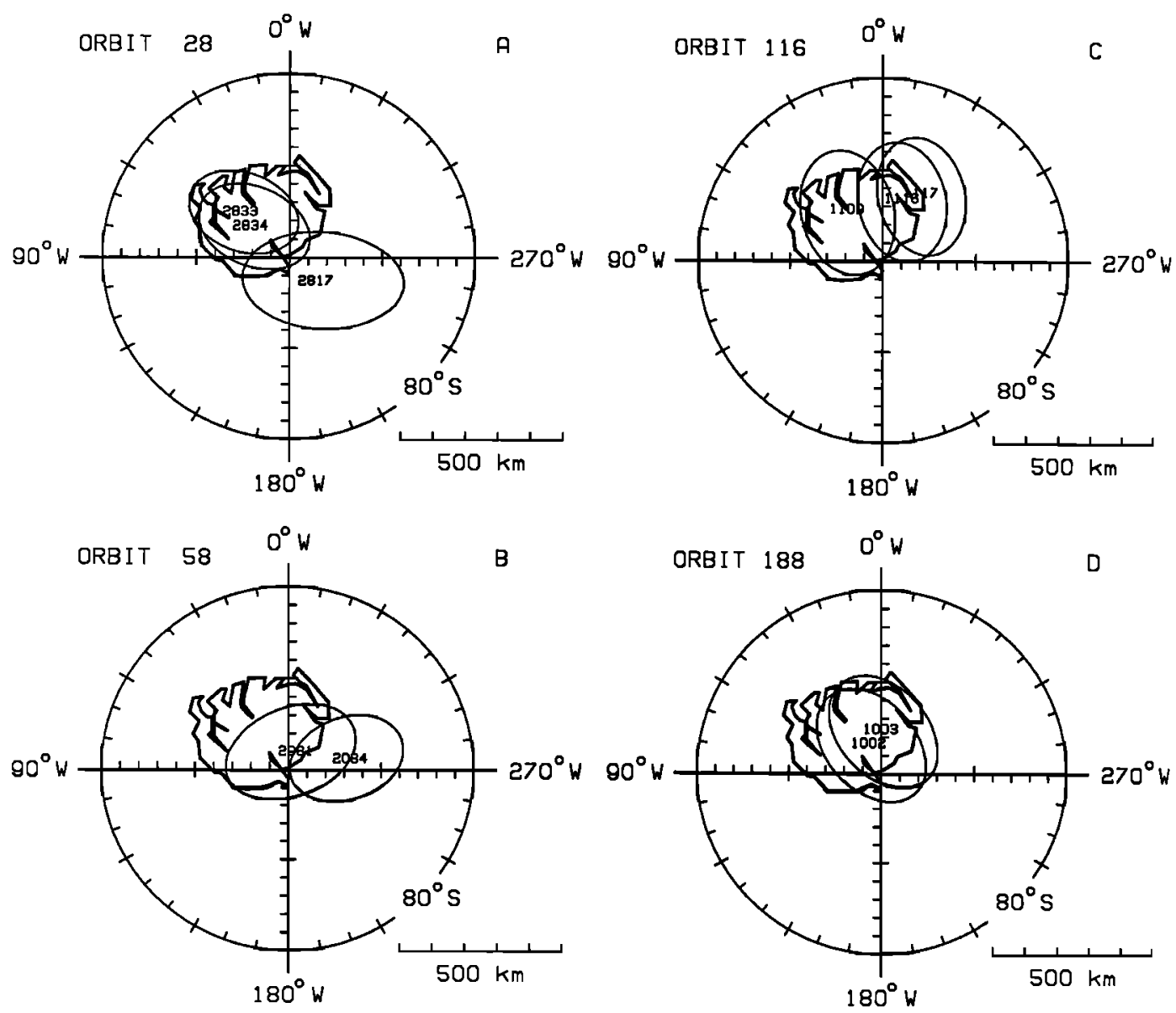

Fig. 5. Maps of the south polar region showing the south residual polar cap the locations of the midpoints of the IRIS spectra used in this study.

mainly due to beam bending in the vidicon, was also removed. After these procedures the resulting images closely approximated the actual scenes observed. Although considerable effort has gone into the calibration of the Mariner 9 television data [Seidman et al., 1973; Herkenhoff et al., 1988], significant radiometric errors remain. To minimize these errors whenever possible, we chose images obtained through the orange filter (effective wavelength of $0.61 \mu$ ), for which the most complete set of calibration data exists. The absolute accuracy of the derived reflectance for each pixel in these images is about $20 \%$ (estimated from comparison with Viking Orbiter images of Phobos), while the relative accuracy is about $10 \%$ [Herkenhoffet al., 1988]. The images used for the orbit 188 analysis were obtained through the $60^{\circ}$ polarizing filter (effective wavelength of $0.57 \mu$ ), for which uncertainties in derived reflectance are slightly higher.

Lambert albedos were determined by dividing pixel values by the cosines of the local solar zenith angles, as calculated using the SEDR data. Because the spectral reflectance of Mars varies significantly in visible light, the Lambert albedos derived from images taken through the orange or $60^{\circ}$ polarizing filter are not equal to the bolometric albedo. Approximate bolometric albedos were therefore derived by comparing Mariner 9 and Earth-based spectral reflectance measurements of Arabia.

Spectral geometric albedo measurements of Arabia by

TABLE 1. Geometry and Ephemerıs Data for the Midpoints of the Mariner 9 IRIS Spectra Used in This Study

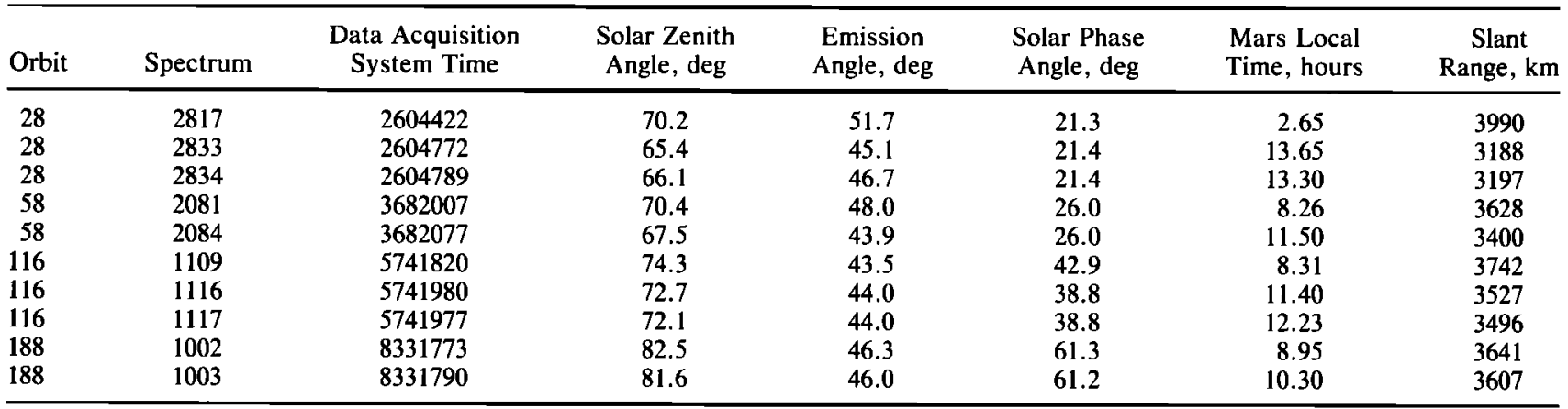



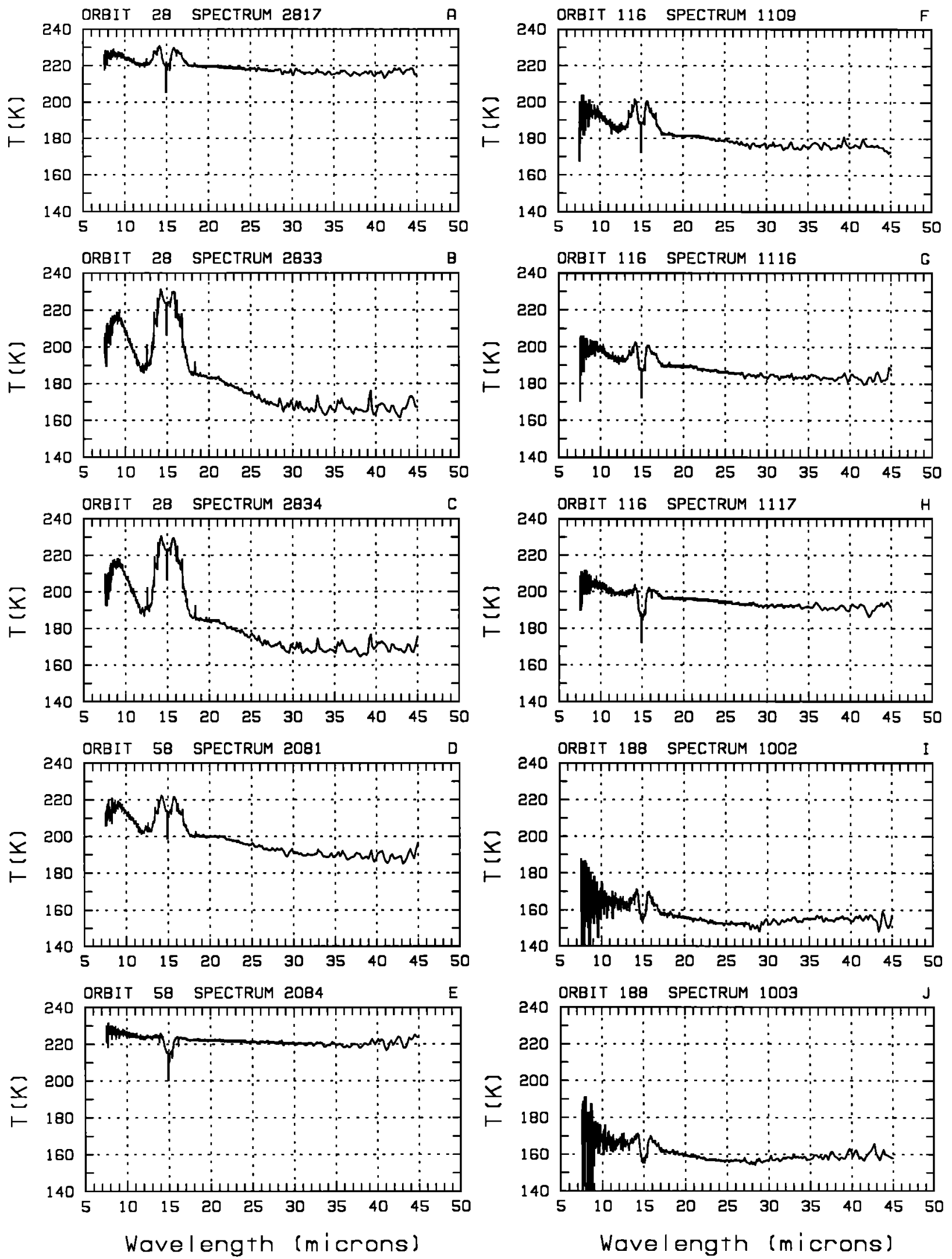

Fig. 6. Mariner 9 IRIS brightness temperature spectra used in this study. 


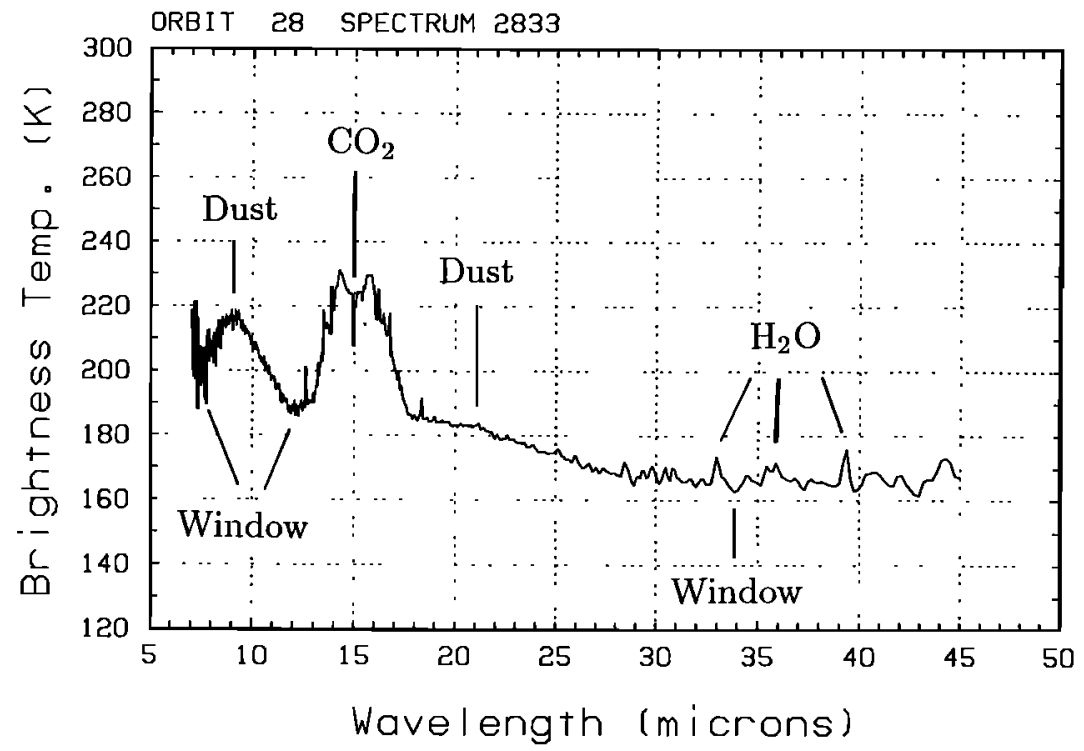

Fig. 7. Mariner 9 IRIS spectrum of the south polar cap of Mars obtained on orbit 28. Labels point to emission features due to gaseous $\mathrm{CO}_{2}$ and $\mathrm{H}_{2} \mathrm{O}$ and atmospheric dust. Also shown are the locations of atmospheric window regions at $\lambda=7.5,12$, and $34 \mu$.

McCord and Westphal [1971] were weighted by the solar spectral flux from 0.3 to $4.0 \mu$ [Arvesen et al., 1969] to yield a bolometric albedo of 0.30 . By weighting McCord and Westphal's data by the orange filter response, we estimate that the albedo of Arabia as seen through the orange filter would be 0.29 . Similarly, Arabia's albedo through the polarizing filter would be 0.20 . The actual spectral reflectances of the south polar frosts and surrounding terrain are not known, so we have assumed that the spectral reflectance of the surrounding terrain is similar to that of Arabia and that the spectral reflectances of the frosts are similar to those of grey reflectors. We have also assumed that the color of the surface of Mars is independent of phase angle, since such effects have not been accurately quantified. With these assumptions, measured orange filter or polarizing filter reflectances were converted to bolometric reflectances by multiplying them by a constant factor.

For combined analysis with the IRIS observations the smeared footprints of the IRIS spectra described in the previous section were located within the images. To determine the exact regions sampled, the locations of the spectra were interpolated at nine points in time during the 21-s IRIS integration periods as shown in Figures 1 and 3. Albedo histograms for the regions sampled by the IRIS spectra were then computed to determine the proportions of dark and light materials within the IRIS fields of view. These histograms are shown in Figure 8.

The albedos presented in the histograms are also affected by dust in the Martian atmosphere. Mariner 9 arrived at Mars during the subsiding phase of the 1971 global dust storm. Although the atmosphere at the south pole appeared to be less dusty than at more equatorward latitudes, it still contained significant quantities of dust during the summer season. At orbit 28, Pang and Hord [1973] have estimated the dust opacity over the south polar cap to be 0.8 at $\lambda=0.3$ $\mu$, with it decreasing to 0.4 by orbit 116 and to 0.1 by orbit 188. If the dust optical properties given by Pollack [1982] are assumed, then dust opacities at the wavelength of the Mariner 9 orange camera filter would be approximately $10 \%$ greater than those at $0.3 \mu$.

The albedos we report in the histograms are not estimates of actual surface albedo. In general, the reflectances of these regions are not isotropic, so the Lambert albedos we report will not necessarily be valid over a wide range of illumination and observing geometries. Also, scattering models show that one of the major effects of atmospheric dust is to decrease apparent surface albedo contrasts. Atmospheric dust tends to make bright surfaces appear darker, and dark surfaces appear brighter [Thorpe, 1979; Davies, 1979; Paige and Ingersoll, 1985]. Changes in the histogram albedos from one orbit to the next are therefore due to the combined effects of changes in atmospheric dust opacity and changes in surface reflectance properties. Despite the effects of atmospheric dust, the boundaries of frosted and unfrosted regions within the IRIS fields of view are clearly visible in the images used in this study. This is also evident in the histograms, which

TABLE 2. Geometry and Ephemeris Data for the Centers of the Mariner 9 Images Used in This Study

\begin{tabular}{|c|c|c|c|c|c|c|}
\hline Picture & $\begin{array}{c}\text { Data Acquisition } \\
\text { System Time }\end{array}$ & $L_{\jmath}, \mathrm{deg}$ & $\begin{array}{c}\text { Emission } \\
\text { Angle, deg }\end{array}$ & $\begin{array}{l}\text { Solar Zenith } \\
\text { Angle, deg }\end{array}$ & $\begin{array}{c}\text { Solar Phase } \\
\text { Angle, deg }\end{array}$ & $\begin{array}{c}\text { Slant } \\
\text { Range, km }\end{array}$ \\
\hline 28A22 & 2604490 & 301 & 52 & 70 & 22 & 3839 \\
\hline $116 \mathrm{Al} 10$ & 5741993 & 326 & 45 & 72 & 39 & 3514 \\
\hline $188 \mathrm{~A} 3$ & 8331859 & 345 & 51 & 85 & 56 & 3651 \\
\hline
\end{tabular}



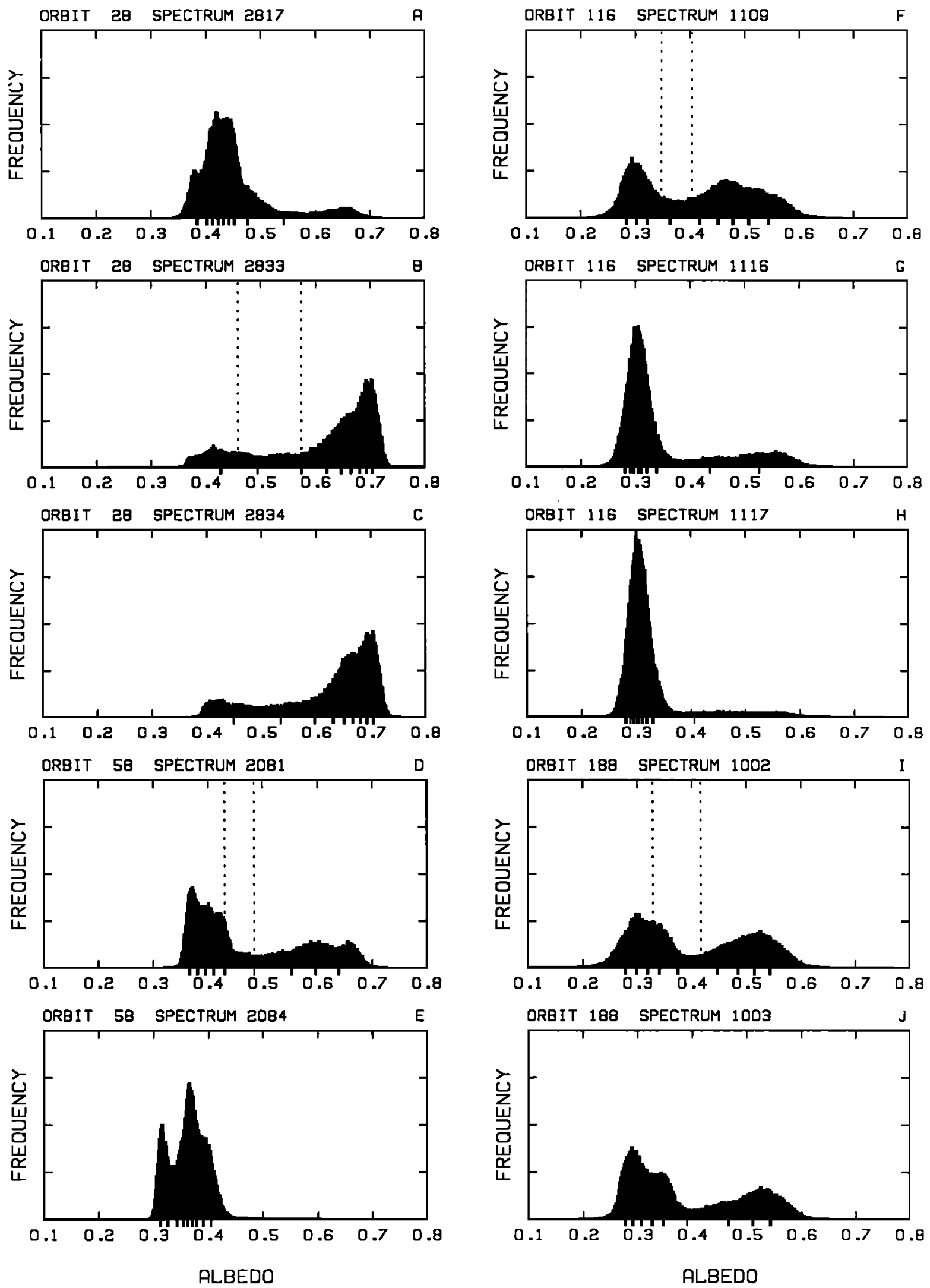

Fig. 8. Calibrated Lambert albedo histograms for the regions sampled by the IRIS spectra used in this study. The downward tick marks along the bottom scales show cumulative histogram fractions at $10 \%$ intervals. The vertical dashed lines show estimated upper and lower limits for maximum albedo of bare ground material for the spectra selected for analysis. 
generally show bimodal distributions of measured reflectance. These histograms will be used to infer the proportions of dark and light material within the IRIS fields of view.

\section{Multispectral Thermal Emission Models}

The principal goal of this study is to determine if the south residual polar cap of Mars contained exposed $\mathrm{CO}_{2}$ frost throughout the summer season of 1971-1972. $\mathrm{CO}_{2}$ frost can be distinguished from water ice by its thermal emission, which is related to its physical temperature. Martian $\mathrm{CO}_{2}$ frost physical temperatures are confined to a narrow range because the frost is in solid-vapor equilibrium with $\mathrm{CO}_{2}$ gas in the Martian atmosphere. The expected temperatures of Martian $\mathrm{CO}_{2}$ frost deposits range from $151 \mathrm{~K}$ for a surface partial $\mathrm{CO}_{2}$ pressure of $10 \mathrm{mbar}$ to $140 \mathrm{~K}$ for a surface partial $\mathrm{CO}_{2}$ pressure of 2 mbar. The Viking infrared thermal mapper (IRTM) instruments observed surface $\mathrm{CO}_{2}$ temperatures of $142 \mathrm{~K}$ during the early southern fall season of 1977 at the south residual cap [Paige and Ingersoll, 1985].

Water ice deposits on Mars can attain higher surface temperatures than $\mathrm{CO}_{2}$ frost. The effect of latent heat on water ice surface temperatures is negligible, as water vapor is a minor constituent in the Martian atmosphere. As with bare ground surface temperatures, water ice surface temperatures are determined by solar heating, infrared emission, and thermal conduction. Surface water ice temperatures in excess of $205 \mathrm{~K}$ were observed by the Viking IRTM instruments during the northern summer season of 1977 at the north residual cap [Kieffer et al., 1976a].

Determining the composition of the south residual cap from the Mariner 9 IRIS observations would be relatively easy if the field of view of the instrument consisted solely of $\mathrm{CO}_{2}$ frost or solely of water ice. In reality, the IRIS surface footprint was approximately the same size as the residual cap, which means that the observed surface emission was due to a combination of $\mathrm{CO}_{2}$ frost and/or water ice plus unfrosted bare ground. Furthermore, the high-resolution Mariner 9 images show that bare ground is mixed with bright condensate materials at a variety of scales that extend down at least $150 \mathrm{~m}$, which is the limit of resolution of the available imagery. These complicating factors make the analysis of the Mariner 9 south residual cap observations a challenging problem.

In this section we describe two methods for using the available observations to test for the presence of surface $\mathrm{CO}_{2}$ frost. We first describe a two-component model used by Hanel et al. [1972a] and then describe our own threecomponent model and illustrate how it can be used in conjunction with the Mariner 9 observations.

\subsection{Two-Component Model}

In their analysis of the IRIS midsummer south polar observations the original IRIS team used the following procedure to infer the temperature of the south polar cap [Hanel et al., 1972a]. The surface emission was assumed to be a mixture of two thermal components: a cold component consisting of condensates (water ice and/or $\mathrm{CO}_{2}$ ) and a hot component consisting of bare ground. For this model the surface-emission at any wavelength is

$$
I(\lambda)=f_{\text {cold }} B\left(T_{\text {cold }}, \lambda\right)+\left(1-f_{\text {cold }}\right) B\left(T_{\text {hot }}, \lambda\right)
$$

where $I(\lambda)$ is the surface emission at wavelength $\lambda, f_{\text {cold }}$ is the fraction of cold material within the IRIS field of view, $T_{\text {hot }}$ and $T_{\text {cold }}$ are the physical temperatures of the hot and cold components, and $B(T, \lambda)$ is the Planck function at temperature $T$ and wavelength $\lambda$. The model implicitly assumes that both the hot and the cold surface materials have unit emissivities. Hanel et al. [1972a] averaged six IRIS spectra with varying fractions of polar cap coverage obtained during orbits 29 and 30 to obtain measured radiances at three wavelengths: $7.52,11.90$, and $33.89 \mu$. The measured radiances at these window wavelengths are assumed to be unaffected by the atmosphere. By solving the following set of three nonlinear equations,

$$
I(7.52)=f_{\text {cold }} B\left(T_{\text {cold }}, 7.52\right)+\left(1-f_{\text {cold }}\right) B\left(T_{\text {hot }}, 7.52\right)
$$$$
I(11.90)=f_{\text {cold }} B\left(T_{\text {cold }}, 11.90\right)
$$

$$
+\left(1-f_{\text {cold }}\right) B\left(T_{\text {hot }}, 11.90\right)
$$

$I(33.89)=f_{\text {cold }} B\left(T_{\text {cold }}, 33.89\right)+\left(1-f_{\text {cold }}\right) B\left(T_{\text {hot }}, 33.89\right)$

values for $T_{\text {hot }}, T_{\text {cold }}$, and $f_{\text {cold }}$ were obtained that were consistent with the IRIS observations at the three wavelengths. Surface temperatures of $140 \pm 10 \mathrm{~K}$ were determined for the frost, and surface temperatures of $235 \pm 10 \mathrm{~K}$ were determined for the bare ground, with average frost coverage of $65 \% \pm 5 \%$.

In Figure 9 we illustrate the behavior of a two-component model and compare the results with an IRIS spectrum obtained on orbit 28 . We assume a hot component temperature of $235 \mathrm{~K}$, a cold component temperature of $133 \mathrm{~K}$, and fractional cold component coverage ranging from 0 to $100 \%$. The model gives a reasonable fit to the IRIS data in the three atmospheric window regions if the fractional cold component coverage is assumed to be approximately $75 \%$. These results are consistent with the results of Hanel et al. [1972a]. The higher fractional cold component coverage inferred by our calculations can be explained by higher actual frost coverage in our single chosen spectrum.

While the results of Hanel et al. [1972a] are consistent with the presence of seasonal $\mathrm{CO}_{2}$ frost at the south polar cap during early summer, they do not address the more important question of what happened later on in the season when residual frost deposits were exposed. Mariner 9 narrow-angle camera images show significant defrosting and darkening of the south residual cap during late summer. The "broken-up" appearance of the residual cap during late summer has been cited as evidence that all the solid $\mathrm{CO}_{2}$ disappeared, exposing a residual water ice cap [Murray et al., 1972].

We have attempted to apply the three-wavelength method to south polar cap spectra from later in the mission, but the results were not reliable. Uniquely fitting a two-component model to a spectrum at three wavelengths requires hightemperature contrasts between $T_{\text {hot }}$ and $T_{\text {cold }}$ and high signal-to-noise ratios at all three wavelengths. The original IRIS team found it necessary to average six south polar spectra to obtain sufficiently high signal-to-noise ratios at $\lambda=7.52 \mu$ to obtain an acceptable fit. Figure 6 shows that the IRIS brightness temperature spectra became progressively colder and "flatter" throughout the summer season. The cold brightness temperatures resulted in very low signalto-noise ratios at short wavelengths. The absence of highquality data at $7.52 \mu$ makes it impossible to uniquely fit the spectra at three wavelengths later in the mission. 


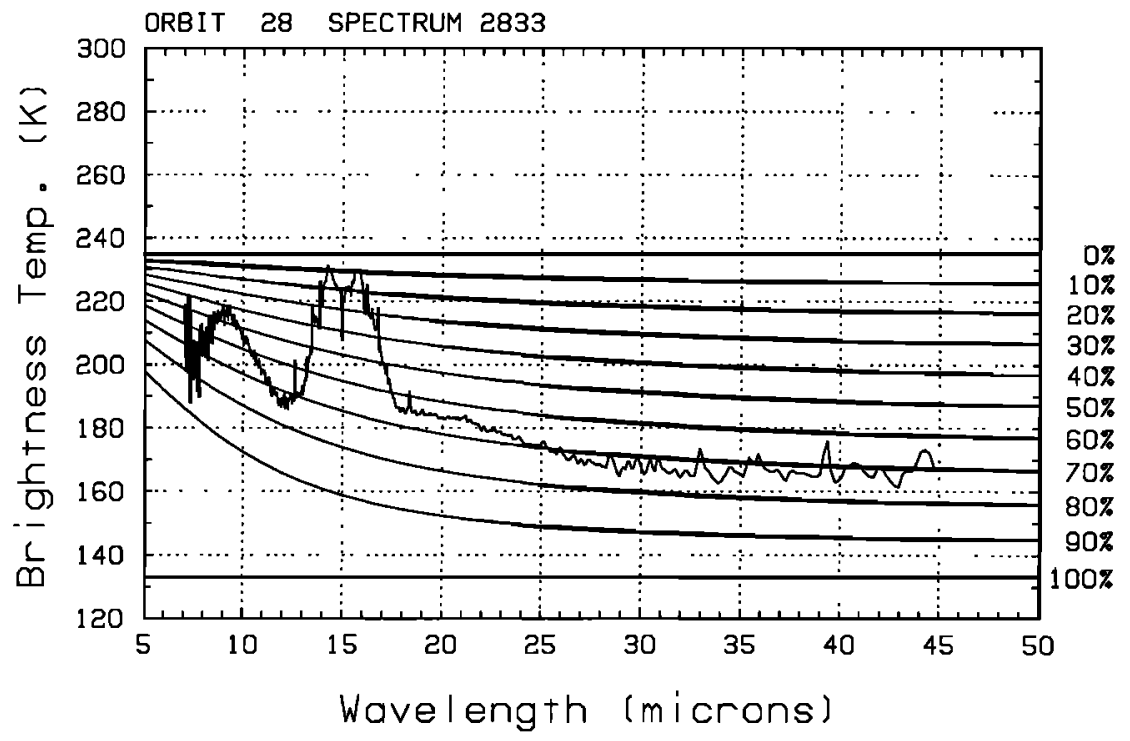

Fig. 9. Calculated brightness temperatures from a two-component model and measured brightness temperatures from an IRIS polar cap spectrum obtained on orbit 28 . The model calculations assume a warm component temperature of $235 \mathrm{~K}$, a cold component temperature of $133 \mathrm{~K}$, and warm surface fractions ranging from 0 to $100 \%$.

\subsection{Three-Component Model}

A more general approach to modeling the IRIS polar spectra is to assume that the surface emission consists of three thermal components: bare ground, $\mathrm{CO}_{2}$ frost, and water ice. For this situation the surface emission at any wavelength is

$$
I(\lambda)=f_{\mathrm{CO}_{2}} B\left(T_{\mathrm{CO}_{2}}, \lambda\right)+f_{\mathrm{H}_{2} \mathrm{O}} B\left(T_{\mathrm{H}_{2} \mathrm{O}}, \lambda\right)+f_{g} B\left(T_{g}, \lambda\right)
$$

where $T_{\mathrm{CO}_{2}}$ and $f_{\mathrm{CO}_{2}}$ are the temperature and fractional coverage of $\mathrm{CO}_{2}$ frost, $T_{\mathrm{H}_{2} \mathrm{O}}$ and $f_{\mathrm{H}_{2} \mathrm{O}}$ are the temperature and fractional coverage of water ice, and $T_{g}$ and $f_{g}$ are the temperature and fractional coverage of bare ground within an IRIS field of view. The model reduces to a twocomponent model if either $f_{\mathrm{CO}_{2}}$ or $f_{\mathrm{H}_{2} \mathrm{O}}$ is assumed to be zero.

The three-component model can be used in conjunction with the Mariner 9 data as follows: $I(\lambda)$ can be reliably determined from single-IRIS spectra throughout the summer season at $\lambda=12$ and $\lambda=34 \mu$. Further constraints can be obtained from the Mariner 9 images. Figure 8 shows histograms of the distributions of observed albedo values for the regions sampled by each of the selected IRIS spectra. The population of albedo values in each histogram is related to the fractional coverage of the three surface components $f_{\mathrm{CO}_{2}}$, $f_{\mathrm{H}_{2} \mathrm{O}}$, and $f_{g}$. Of the three components the fractional bare ground coverage $f_{g}$ can be inferred most directly from the histograms. This can be accomplished by using histograms of regions adjacent to the residual cap to determine the maximum albedo of unfrosted bare ground material within the regions sampled by each IRIS spectra. Once $f_{g}$ has been estimated, the remainder of the region sampled must then contain water ice and/or $\mathrm{CO}_{2}$ frost.

The three-component model gives the following system of equations:

$I(12)=f_{\mathrm{CO}_{2}} B\left(T_{\mathrm{CO}_{2}}, 12\right)+f_{\mathrm{H}_{2} \mathrm{O}} B\left(T_{\mathrm{H}_{2} \mathrm{O}}, 12\right)+f_{g} B\left(T_{g}, 12\right)$

$I(34)=f_{\mathrm{CO}_{2}} B\left(T_{\mathrm{CO}_{2}}, 34\right)+f_{\mathrm{H}_{2} \mathrm{O}} B\left(T_{\mathrm{H}_{2} \mathrm{O}}, 34\right)+f_{g} B\left(T_{g}, 34\right)$

$$
f_{\mathrm{CO}_{2}}+f_{\mathrm{H}_{2} \mathrm{O}}+f_{g}=1
$$

with $I(12), I(34)$, and $f_{g}$ as observed quantities and $T_{\mathrm{CO}_{2}}$, $T_{\mathrm{H}_{2} \mathrm{O}}, T_{g}$, and $f_{\mathrm{CO}_{2}}$ or $f_{\mathrm{H}_{2} \mathrm{O}}$ as unknowns.

Our method for using the observations to constrain the unknown quantities can be illustrated by considering three test cases. In Table 3 we show three sets of values for $f_{g}, T_{g}$, $f_{\mathrm{H}_{2} \mathrm{O}}, T_{\mathrm{H}_{2} \mathrm{O}}, f_{\mathrm{CO}_{2}}$, and $T_{\mathrm{CO}_{2}}$. Case 1 assumes an IRIS field of view consisting of $40 \%$ bare ground and $60 \% \mathrm{CO}_{2}$ frost. Case 2 assumes $40 \%$ bare ground and $60 \%$ water ice. Case 3 assumes $40 \%$ bare ground, $30 \%$ water ice, and $30 \% \mathrm{CO}_{2}$ frost. The temperatures of the three components were chosen to roughly approximate those expected for orbit 116 . Also shown in Table 3 are calculated values for $I(\lambda=12 \mu)$ and $I(\lambda=34 \mu)$ for the three cases.

From a mathematical standpoint this problem is not well posed because (4), (5), and (6) have four unknown parameters $\left(T_{\mathrm{CO}_{2}}, T_{\mathrm{H}_{2} \mathrm{O}}, T_{g}\right.$, and $f_{\mathrm{CO}_{2}}$ or $\left.f_{\mathrm{H}_{2} \mathrm{O}}\right)$ and only three observables $\left(I(12), I(34)\right.$, and $f_{g}$ ). The problem is further compounded by the fact that the observed quantities them-

TABLE 3. Three Sets of Three-Component Model Input Parameters and the Resulting Brightness Temperatures at $\lambda=12$ and $34 \mu$

\begin{tabular}{ccccccccc}
\hline Test Case & $f_{g}$ & $T_{g}, \mathrm{~K}$ & $f_{\mathrm{CO}_{2}}$ & $T_{\mathrm{CO}_{2}, \mathrm{~K}}$ & $f_{\mathrm{H}_{2} \mathrm{O}}$ & $T_{\mathrm{H}_{2} \mathrm{O}}, \mathrm{K}$ & $T_{b}(12), \mathrm{K}$ & $T_{b}(34), \mathrm{K}$ \\
\hline 1 & 0.4 & 205 & 0.6 & 142 & 0.0 & $\ldots$ & 180.0 & 169.8 \\
2 & 0.4 & 205 & 0.0 & $\ldots$ & 0.6 & 160 & 184.2 & 179.1 \\
3 & 0.4 & 205 & 0.3 & 142 & 0.3 & 160 & 182.2 & 174.5 \\
\hline
\end{tabular}


selves have uncertainties associated with them. Our method for attacking this problem is to vary $f_{g}$ within its range of uncertainty; to vary each of the unknown parameters in (4), (5), and (6) over a wide range; and then to discard all combinations of these unknown parameters that yield calculated values of $I(\lambda=12 \mu)$ and $I(\lambda=34 \mu)$ that do not agree with the IRIS observations at these two wavelengths to within their measured uncertainties. For the examples shown here, we will assume that $f_{g}$ is known to an accuracy of \pm 0.05 and $I(\lambda=12 \mu)$ and $I(\lambda=34 \mu)$ are known to an accuracy of $\pm 1 \mathrm{~K}$. These uncertainties are representative of those of the Mariner 9 observations we use later. We also assume that the maximum permissible surface $\mathrm{CO}_{2}$ frost temperature is $150 \mathrm{~K}$ and that bare ground temperatures can range anywhere from $180 \mathrm{~K}$ to $220 \mathrm{~K}$. Allowing for $\mathrm{CO}_{2}$ frost temperatures that are significantly lower than $140 \mathrm{~K}$ accounts for the possibility that actual $\mathrm{CO}_{2}$ frost emissivities may be less than unity. Possible water ice temperatures are assumed to be greater than or equal to $\mathrm{CO}_{2}$ frost temperatures but less than bare ground temperatures for all combinations of input values.

The results of the test calculations with the threecomponent model are summarized in Figure 10, which shows bare ground, water ice, and $\mathrm{CO}_{2}$ frost temperatures as a function of fractional $\mathrm{CO}_{2}$ frost coverage. The figures were generated by computing $I(\lambda=12 \mu)$ and $I(\lambda=34 \mu)$ for over 1.6 million combinations of $T_{\mathrm{CO}_{2}}, T_{\mathrm{H}_{2} \mathrm{O}}, T_{g}, f_{g}$, and $f_{\mathrm{CO}_{2}}$ and then shading those regions of the parameter space that contained combinations of these parameters that yielded calculated values of $I(\lambda=12 \mu)$ and $I(\lambda=34 \mu)$ that were within $1 \mathrm{~K}$ of their true values.

The figures show that the results of this procedure are far from unique. The observed quantities are consistent with a wide range of bare ground, water ice, and $\mathrm{CO}_{2}$ frost temperatures. Of the three components, bare ground temperatures are the best constrained. Water ice temperatures are well constrained only when the fractional coverage of $\mathrm{CO}_{2}$ is assumed to approach zero. $\mathrm{CO}_{2}$ frost temperatures are well constrained only when the fractional coverage of water ice is assumed to approach zero.

The only example that truly requires the presence of $\mathrm{CO}_{2}$ frost for all possible combinations of input parameters is test case 1 . This can be seen by observing the behavior of the three-component model results when $f_{\mathrm{CO}_{2}}$ is assumed to be zero. For test case 1, water ice temperatures would be required to be in the range of $132.5-150 \mathrm{~K}$ if $\mathrm{CO}_{2}$ frost was not assumed to be present. This means, in essence, that $\mathrm{CO}_{2}$ frost must be present, since surfaces at these temperatures condense atmospheric $\mathrm{CO}_{2}$. Examination of the middle and bottom plots of Figure 10 shows that the results of test cases 2 and 3 are less clear. Test case 2 gives water ice temperatures of $152.5-170 \mathrm{~K}$ when $f_{\mathrm{CO}_{2}}$ is assumed to be zero. Test case 3 gives water ice temperatures of $142.5-160 \mathrm{~K}$ when $f_{\mathrm{CO}_{2}}$ is assumed to be zero. The main conclusion that can be drawn from these examples is that this method yields definitive results only in cases where bare ground and $\mathrm{CO}_{2}$ frost predominate. In the next section we apply this analysis technique to actual Mariner 9 observations and present the results.

\section{Results}

For our analysis we have selected the spectrum in each orbit that has the coldest brightness temperatures and the
TEST CASE 1

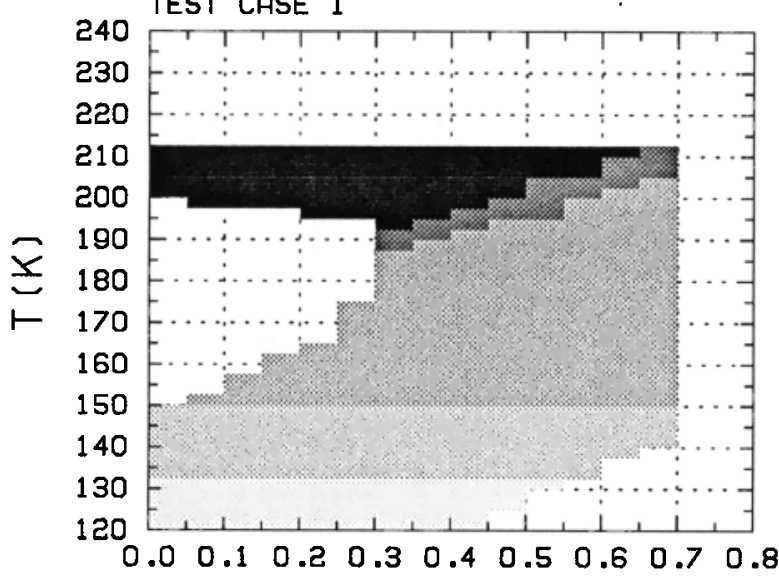

TEST CASE 2

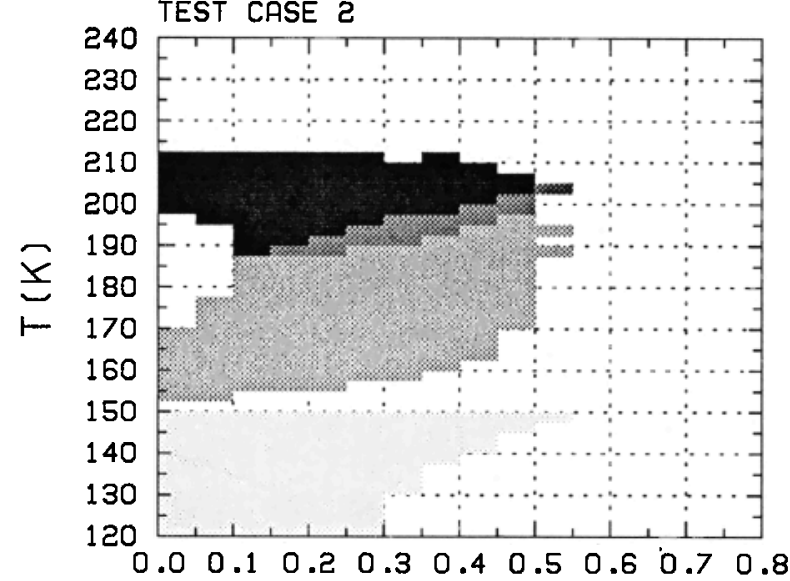

TEST CASE 3

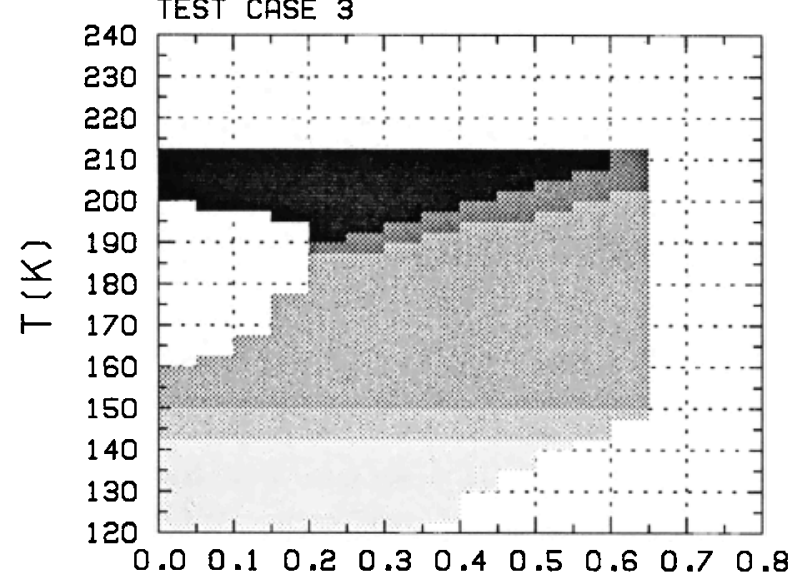

$\mathrm{fCO}_{2}$

$g=\mathrm{g}^{+\mathrm{H}_{2} \mathrm{O}}=\mathrm{H}_{2} \mathrm{O}=\mathrm{H}_{2} \mathrm{O}+\mathrm{CO}_{2}$

$\mathrm{CO}_{2}$

Fig. 10. Three-component model results for three test cases. True values for temperature and fractional coverage of bare ground, water ice, and $\mathrm{CO}_{2}$ frost for each test case are presented in Table 3. The stippled regions show the range of model-calculated bare ground, water ice, and $\mathrm{CO}_{2}$ frost temperatures that yield brightness temperatures at $\lambda=12$ and $34 \mu$ that are within $\pm 1 \mathrm{~K}$ of their true values as a function of $f_{\mathrm{CO}_{2}}$, the assumed fraction of the field of view containing $\mathrm{CO}_{2}$ frost. Overlapping regions are denoted by intermediate densities of stippling. Test case 1 assumes that only bare ground and $\mathrm{CO}_{2}$ frost are present. Test case 2 assumes that only bare ground and water ice are present. Test case 3 assumes that bare ground, water ice, and $\mathrm{CO}_{2}$ frost are present. 
TABLE 4. IRIS $12-\mu$ and 34- $\mu$ Brightness Temperatures, Standard Deviations, and Upper and Lower Limits for Bare Ground Coverage for the Four Spectra Selected for Combined Analysis

\begin{tabular}{|c|c|c|c|c|c|c|c|}
\hline \multirow[b]{2}{*}{ Orbit } & \multirow[b]{2}{*}{ Spectrum } & \multicolumn{2}{|c|}{$\lambda=12 \mu$} & \multicolumn{2}{|c|}{$\lambda=34 \mu$} & \multirow[b]{2}{*}{$f_{g}$ Minimum } & \multirow[b]{2}{*}{$f_{g}$ Maximum } \\
\hline & & $T_{b}, \mathrm{~K}$ & $\sigma, \mathbf{K}$ & $T_{b}, \mathbf{K}$ & $\sigma, \mathbf{K}$ & & \\
\hline 28 & 2833 & 188.33 & 1.14 & 163.64 & 0.74 & 0.15 & 0.30 \\
\hline 58 & 2081 & 202.38 & 0.55 & 188.80 & 0.14 & 0.50 & 0.60 \\
\hline 116 & 1109 & 185.64 & 1.21 & 174.45 & 0.48 & 0.37 & 0.47 \\
\hline 188 & 1002 & 162.91 & 1.10 & 153.48 & 0.29 & 0.35 & 0.55 \\
\hline
\end{tabular}

greatest fractional condensate coverage. Brightness temperatures at $\lambda=12 \mu$ and $\lambda=34 \mu$ were determined by averaging the measured IRIS radiances over a $5.85-\mathrm{cm}^{-1}$ passband. Uncertainties in the measured brightness temperatures due to instrumental noise were determined by computing the standard deviations of the brightness temperatures in the passbands. Computed effective noise-equivalent radiances using this technique are in excellent agreement with those determined by Hanel et al. [1973] at these two wavelengths. Average brightness temperatures and standard deviations at $\lambda=12 \mu$ and $\lambda=34 \mu$ for these IRIS spectra are presented in Table 4 . Actual total uncertainties in the surface emission at these two wavelengths are greater than those listed in Table 4 because of uncertainties in absolute calibration and atmospheric opacity. Although these additional sources of uncertainty are difficult to quantify precisely, the discussions presented in section 2 of this paper indicate they are small. In the following analysis we will assume that the total uncertainties in the surface emission brightness temperatures at these two wavelengths are equal to the standard deviations shown in Table 4 plus an additional $\pm 1 \mathrm{~K}$ for absolute calibration and atmospheric opacity.

Upper and lower limits for the fractional bare ground coverage $f_{g}$ were determined for each of the selected IRIS spectra by examining the histograms shown in Figure 8 . The limits were determined by using histograms of regions within the same frame adjacent to the residual cap to determine the maximum albedo of unfrosted bare ground material. All regions within the IRIS footprint with albedos greater than this maximum bare ground value were then classified as water ice and/or $\mathrm{CO}_{2}$ frost. Although our determinations of $f_{g}$ are not expected to be significantly affected by uncertainties in absolute calibration or dust opacity, they are affected by uncertainties in the positions of the IRIS footprints relative to the wide-angle camera images. Scan platform pointing knowledge errors of up to $0.1^{\circ}$ of are [Blasius, 1973] are present in both the IRIS and the imaging data sets. Since these data were generally not obtained at the same points in a given orbit, the locations of the IRIS footprints relative to the images could be in error by up to $0.2^{\circ}$ of arc. This corresponds to offsets of approximately 15 pixels for the images used here. We have found that arbitrary offsets of the footprints of this magnitude can significantly affect the shapes of the histograms only in cases where the percentage of bare ground or frost coverage is very small. To minimize possible errors due to pointing knowledge uncertainties, we have performed our analysis only on spectra that sampled substantial fractions of the south polar cap. Possible uncertainties in $f_{g}$ due to uncertainties in knowledge of the relative positions of the IRIS footprints within the wide-angle camera images were estimated by offsetting the IRIS footprints relative to the core of the residual cap by \pm 15 pixels. For the spectra selected for analysis this procedure resulted in changes in the estimated values of $f_{g}$ of less than \pm 0.05 . Estimated upper and lower limits of $f_{g}$ for the spectra used in our analysis are presented in Table 4 and in Figure 8. It is important to point out that our upper limits for $f_{g}$ include significant portions of the histograms that have intermediate brightnesses. Recent analyses of Viking multispectral observations of intermediate albedo surface units in the vicinity of the south residual cap show that frost and bare ground are mixed well below the spatial resolution of the Viking orbiter images [Herkenhoff and Murray, 1989]. Including this material in our estimates of $f_{g}$ accounts for the possibility that there may be hot dark regions mixed with cold bright regions at spatial scales that are beyond the resolution of the Mariner 9 wide-angle images.

The results of our analysis with the three-component model are shown in Figure 11. Examination of the plots shows that the results are reminiscent of the test cases in many respects. Bare ground temperatures are well constrained. Water ice temperatures are not well constrained, except when $f_{\mathrm{CO}_{2}}$ is assumed to be zero. The most important aspect of the model results is that when the fractional $\mathrm{CO}_{2}$ frost coverage is assumed to be zero, water ice temperatures are always close to or less than $150 \mathrm{~K}$. As demonstrated in the test cases in the last section, this is the only situation in which the model gives unambiguous results, the result in this case being that $\mathrm{CO}_{2}$ frost must be present for all orbits.

The time evolution of the results of our analysis is shown in Figure 12. Derived upper and lower limits for bare ground, water ice, and $\mathrm{CO}_{2}$ frost temperatures are plotted for all four orbits as a function of season. Also shown are calculated surface temperatures for exposed water ice caps at a latitude of $-88^{\circ}$ from Kieffer [1979]. The calculations are intended to show the minimum temperatures that an exposed water ice cap would attain if exposed at four different dates during southern summer. Calculated surface heating rates do not include the effects of atmospheric dust. The calculations assume a surface albedo of 0.5 and a surface and subsurface thermal inertia of $50 \times 10^{-3} \mathrm{cal} \mathrm{cm}^{-2} \mathrm{~s}^{-1 / 2} \mathrm{~K}^{-1}$. The assumed thermal inertia is consistent with the thermal properties of solid water ice. The calculations show that an exposed water ice cap could reach surface temperatures of at least $170 \mathrm{~K}$, even if it was exposed late in the summer season.

\section{Discussion}

Before discussing some of the larger implications of our results, we first consider aspects of our results that can be tested for internal consistency or by independent means. 

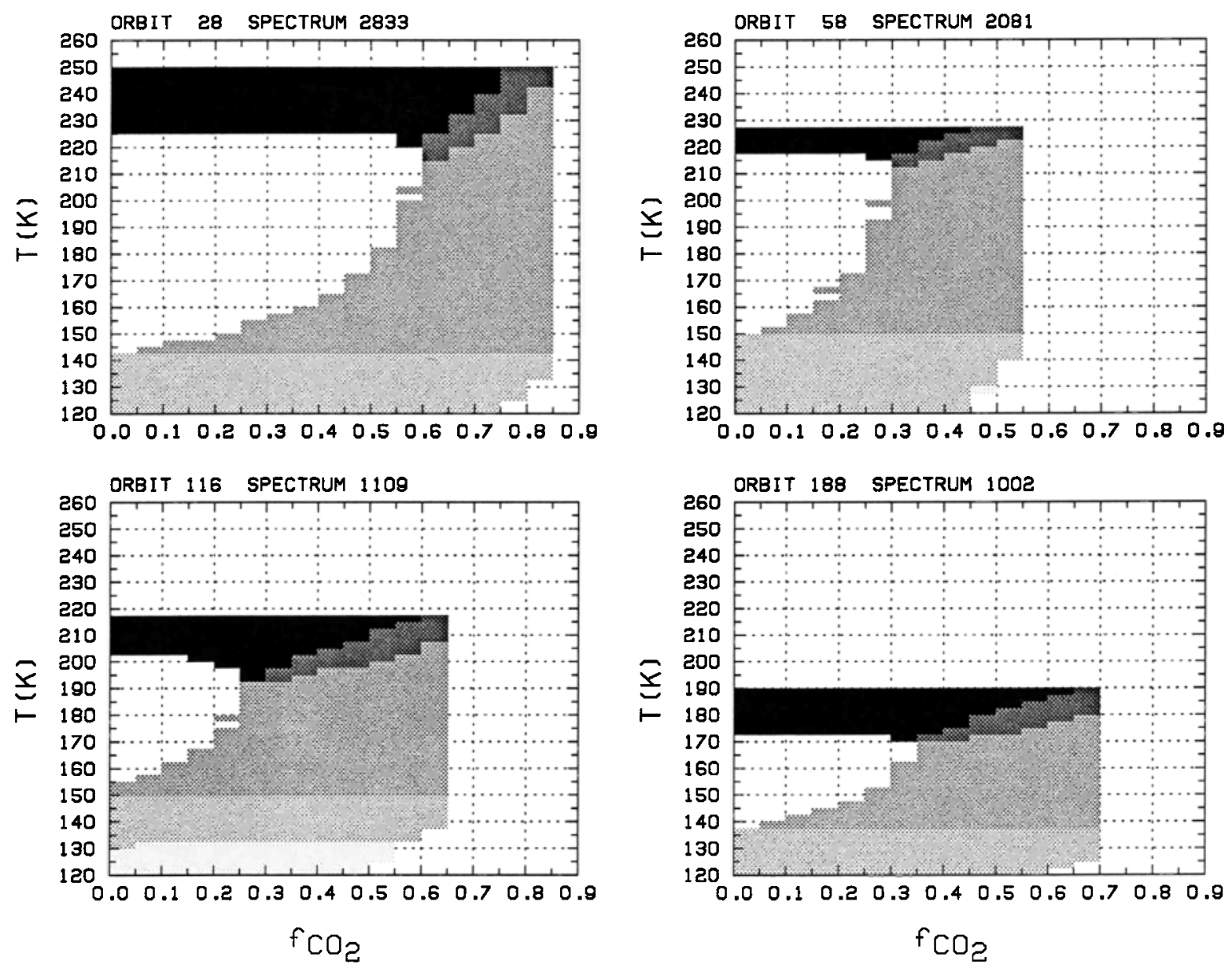

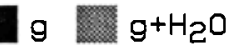

$\mathrm{H}_{2} \mathrm{O}$

$\mathrm{H}_{3} \mathrm{O}+\mathrm{CO}_{5}$

$\mathrm{CO}_{2}$

Fig. 11. Three-component model results for four IRIS spectra of the south polar cap obtained on orbits 28, 58, 116, and 188. The stippled regions show the range of model-calculated bare ground, water ice, and $\mathrm{CO}_{2}$ frost temperatures that yield brightness temperatures at $\lambda=12$ and $34 \mu$ that agree with the IRIS observations to within their estimated uncertainties as a function of $f_{\mathrm{CO}_{2}}$, the assumed fraction of the field of view containing $\mathrm{CO}_{2}$ frost. Overlapping regions are denoted by intermediate densities of stippling.

Our inferred bare ground temperatures can be tested by comparing them with IRIS brightness temperatures for bare ground regions surrounding the south polar cap. Orbit 58 spectrum 2084 and orbit 116 spectrum 1117 can be used for this purpose, since they were obtained at approximately the same latitude as the core region of the south residual polar cap but contain very little frost. Measured brightness temperatures at $\lambda=12 \mu$ of $223 \mathrm{~K}$ for orbit 58 spectrum 2084 and $200 \mathrm{~K}$ for orbit 116 spectrum 1117 are in excellent agreement with our derived bare ground temperatures for spectra obtained within the south polar cap during these orbits.

Our inferred bare ground temperatures can also be tested by comparing them with the results of seasonal thermal model calculations. Figure 12 also shows bare ground surface temperatures calculated at $-88^{\circ}$ latitude using the Viking thermal model [Kieffer et al., 1977]. All three cases assume a surface albedo of 0.3 , which is consistent with our measurements of bare ground albedos within the south polar cap during late summer (see the calibrated histograms in Figure 8). For surface albedos in this range, diurnally averaged surface heating rates and measured albedos at the top of the atmosphere are not significantly altered by the presence of dust in the overlying atmosphere [Davies, 1979; Pollack et al., 1979; Paige, 1985]. The calculations assume thermal inertias of $6 \times 10^{-3}, 20 \times 10^{-3}$, and $50 \times 10^{-3} \mathrm{cal}$ $\mathrm{cm}^{-2} \mathrm{~s}^{-1 / 2} \mathrm{~K}^{-1}$. Although the uncertainties in our derived bare ground temperatures make it difficult to "fit" the thermal model results to infer exact thermal inertias for the bare ground material, the derived bare ground temperatures are well enough constrained to show that they are quite consistent with the results of these calculations for a reasonable set of model input parameters. The agreement between our measured albedos for the bare ground material from the Mariner 9 images and the model albedos that are required to match our derived bare temperatures confirms the accuracy of the calibration procedures that were used on the images. This agreement also provides evidence that the physical assumptions used in the thermal model are valid for the bare ground material within the south polar cap.

Our inferred upper limits for $\mathrm{CO}_{2}$ frost temperatures cannot be tested against other data, but they can be checked for consistency, since they were determined independently for each orbit. On orbit 116 our inferred upper limits for $\mathrm{CO}_{2}$ frost temperatures were only $137.5 \mathrm{~K}$, which could imply 


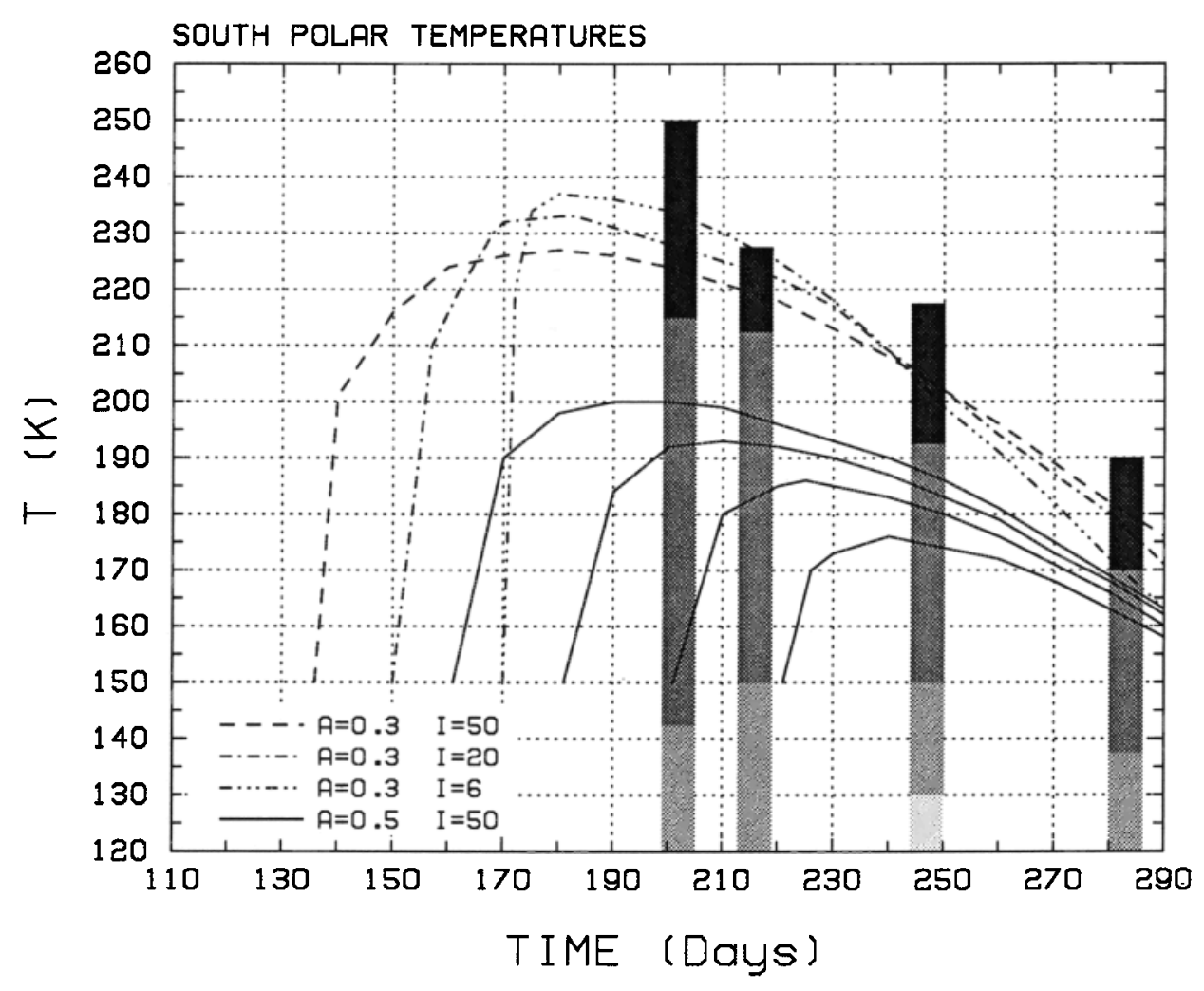

$\mathrm{g}=\mathrm{g}+\mathrm{H}_{2} \mathrm{O}=\mathrm{H}_{2} \mathrm{O}=\mathrm{H}_{2} \mathrm{O}+\mathrm{CO}_{2} \quad \mathrm{CO}_{2}$

Fig. 12. Derived south polar cap bare ground, water ice, and $\mathrm{CO}_{2}$ frost temperatures from the calculations shown in Figure 11 as a function of time. The dashed curves show thermal model calculations of south polar bare ground surface temperatures assuming a surface albedo of 0.3 and surface thermal inertias of $50 \times 10^{-3}, 20 \times 10^{-3}$, and $6 \times$ $10^{-3} \mathrm{cal} \mathrm{cm}^{-2} \mathrm{~s}^{-1 / 2} \mathrm{~K}^{-1}$. The solid curves show thermal model calculations of possible south polar water ice cap temperatures assuming a water ice albedo of 0.5 and a water ice thermal inertia of $50 \times 10^{-3} \mathrm{cal} \mathrm{cm}^{-2} \mathrm{~s}^{-1 / 2} \mathrm{~K}^{-1}$ [from Kieffer, 1979].

that the brightness temperatures of the surface $\mathrm{CO}_{2}$ frost deposits could be lower than their expected values of 142$148 \mathrm{~K}$. We now consider three possible explanations for this result.

A first possibility is that the IRIS brightness temperatures could be miscalibrated. If actual brightness temperatures were $15 \mathrm{~K}$ higher than those reported here, then our results for orbits 58 and 116 would be ambiguous. This possibility can be investigated by comparing the IRIS brightness temperatures with those obtained 3 Mars years later by the Viking infrared thermal mapper (IRTM) instruments. IRTM observed the south polar region of Mars in five infrared wavelength channels centered at wavelengths of $7,9,11,15$, and $20 \mu$. Detailed comparisons between IRTM and IRIS are difficult, because the field of view of IRTM was smaller than that of IRIS, and the surface and atmospheric behavior in the south polar region in 1977 was not the same as it was in 1971. Nonetheless, large discrepancies between these two data sets, if they exist, would be important to document. The bare ground regions surrounding the polar cap provide the best locations for comparing the two data sets. They are better than the polar caps themselves because bare ground temperatures are more spatially uniform and therefore less sensitive to differences in instrument field of view. Also, elevated bare ground brightness temperatures are much less seriously affected by the radiative effects of atmospheric dust. We have compared our IRIS bare ground temperatures with IRTM $20-\mu$ channel bare ground brightness temperatures reported by Kieffer [1979] at the same wavelength, latitude, season, and time of day and found excellent agreement in every case.

A second possible explanation for our low inferred $\mathrm{CO}_{2}$ frost brightness temperatures is that the frost deposits within the south polar cap had less than unit emissivities. During the polar winter seasons, IRTM measured 20- $\mu$ channel brightness temperatures of less than $130 \mathrm{~K}$ [Kieffer et al., $1976 b]$. These anomalous winter season brightness temperatures have been attributed to a variety of possible causes, including local $\mathrm{CO}_{2}$ depletion of the condensing polar atmosphere [Kieffer et al., 1977], low frost emissivity [Kieffer et al., 1977], and $\mathrm{CO}_{2}$ clouds [Hunt, 1980; Paige, 1989]. Of these, only low frost emissivity could be invoked during the summer season because atmospheric temperatures are well above the $\mathrm{CO}_{2}$ frost point. Although the results we present in this study and those of Hanel et al. [1972a] cannot rule out the possibility that the south polar cap contained lowemissivity frost, it should be emphasized that of the three components (bare ground, water ice, and $\mathrm{CO}_{2}$ frost), only $\mathrm{CO}_{2}$ frost has the possibility of having significantly less than unit emissivities at IRIS wavelengths.

A final possible explanation for our lower than expected inferred frost temperatures is that the bare ground regions 
within the IRIS fields of view may not be as thermally homogeneous as we have assumed in our three-component model. Although our analysis accounts for the possibility that the IRIS fields of view may contain dark hot bare ground regions mixed with bright cold frost regions at spatial scales beyond the resolution of the wide-angle camera images, it does not account for the possibility that some of the dark regions may be significantly cooler than others. The seasonal thermal histories of bare ground and water ice regions within the residual cap area are influenced by a number of factors, including date of exposure, insolation, albedo, local topography, bulk thermal properties, and thermal exposure to adjacent $\mathrm{CO}_{2}$ frost deposits. If mixed at sufficiently small spatial scales, horizontal heat transfer between bare ground and $\mathrm{CO}_{2}$ frost deposits could have a significant cooling effect on bare ground materials, particularly toward the end of the summer season when polar insolation is reduced and high solar zenith angles could permit shadowing. We have investigated the impact of the possible presence of dark cold material on our results by repeating our analysis assuming that the IRIS fields of view contained less hot bare ground material than the histograms would indicate. We find that decreasing our assumed lower limits for $f_{g}$ has the effect of raising calculated upper limits for $T_{\mathrm{CO}_{2}}$. For example, if we assume that the lower limit for the bare ground fraction within orbit 188 spectrum 1002 is reduced from 0.35 to 0.25 , our calculated upper limits for $T_{\mathrm{CO}_{2}}$ increase from $137.5 \mathrm{~K}$ to $142.5 \mathrm{~K}$. We therefore conclude that the presence of some cold bare ground material in close thermal contact with $\mathrm{CO}_{2}$ frost is consistent with the available Mariner 9 observations.

On a more general level the existence of residual $\mathrm{CO}_{2}$ frost at the Martian south polar cap during southern summer of 1971-1972 represents an important datum in our expanding record of Martian interannual climatic variability, especially since the residual frost deposits were much less extensive than those observed by Viking in 1977 [James et al., 1979]. The key question of how much excess $\mathrm{CO}_{2}$ is present at the south residual cap hinges almost entirely on the water vapor observations of 1969. If the residual $\mathrm{CO}_{2}$ frost deposits did completely sublimate [Jakosky and Barker, 1984], then the present mass of solid $\mathrm{CO}_{2}$ at the south residual cap must be insignificant. Since the partitioning of available $\mathrm{CO}_{2}$ between atmosphere and polar caps is likely to be extremely sensitive to changes in polar insolation caused by largeamplitude variations in Mars' orbital and axial elements, the apparent current absence of a significant solid $\mathrm{CO}_{2}$ reservoir deserves explanation. Measurements of annual radiation budgets for the core regions of the residual polar caps from Viking observations have shown that $\mathrm{CO}_{2}$ frost is stable at the south residual cap, but not at the north residual cap, because annually averaged albedos of seasonal frost deposits in the south are higher [Paige and Ingersoll, 1985]. These south polar cap albedos appear to be high enough to maintain the deposits at annually averaged temperatures that are consistent with the notion that the vapor pressures of these deposits are determining the present partial pressure of $\mathrm{CO}_{2}$ in the entire Martian atmosphere, just as predicted by the original Leighton and Murray [1966] model. Therefore if the excess residual $\mathrm{CO}_{2}$ frost did in fact disappear in 1969, then the current absence of a significant solid $\mathrm{CO}_{2}$ frost reservoir on Mars is purely coincidental, or there are as yet undefined feedback processes involving the polar caps, atmosphere, and buried $\mathrm{CO}_{2}$ reservoirs that maintain the mass of Martian residual $\mathrm{CO}_{2}$ frost deposits at near-zero levels.

Acknowledgments. We thank Peter Gierasch and Hugh Kieffer for extremely helpful reviews of this manuscript. This research was supported by the NASA Planetary Geology and Geophysics Program.

\section{REFERENCES}

Arvesen, J. C., R. N. Griffin, and B. D. Pearson, Determination of extraterrestrial solar spectral irradiance from a research aircraft, Appl. Opt., 8, 2215, 1969.

Blasius, K. R., A study of Martian topography by analytic photogrametry, J. Geophys. Res., 78, 3311, 1973.

Conrath, B. J., Curran, R. Hanel, V. Kunde, W. Maguire, J. Pearl, J. Pirraglia, J. Welker, and T. Burke, Atmospheric and surface properties of Mars obtained by infrared spectroscopy on Mariner 9, J. Geophys. Res., 78, 4267, 1973.

Curran, R. F., B. J. Conrath, R. A. Hanel, V. G. Kunde, and J. C. Pearl, Mars: Mariner 9 spectroscopic evidence for $\mathrm{H}_{2} \mathrm{O}$ ice clouds, Science, 182, 381, 1973.

Cutts, J. A., Mariner Mars 1971 television picture catalog: Experiment design and picture data, Tech. Memo. 33-585, vol. 1, Jet Propul. Lab., Pasadena, Calif., 1974.

Davies, D. W., Effects of dust heating of Mars' surface and atmosphere, J. Geophys. Res., 84, 8289, 1979.

Fanale, F. P., and W. A. Cannon, Mars $\mathrm{CO}_{2}$ adsorption and capillary condensation on clays: Significance for volatile storage and atmospheric history, J. Geophys. Res., 84, 8404, 1979.

Fanale, F. P., J. R. Salvail, W. B. Banerdt, and R. S. Saunders, Mars: The regolith-atmosphere-cap system and climate change, Icarus, 50, 381, 1982.

Farmer, C. B., D. W. Davies, and D. D. La Porte, Mars: Northern summer ice cap-water vapor observations from Viking 2, Science, 194, 1339, 1976.

Hanel, R. A., B. J. Conrath, W. A. Hovis, V. G. Kunde, P. D. Lowman, J. C. Pearl, C. Prabhakara, B. Schlachman, and G. V. Levin, Infrared spectroscopy experiment on the Mariner 9 mission: Preliminary results, Science, 175, 305, 1972a.

Hanel, R. A., B. Schlachman, E. Breihan, R. Bywaters, F. Chapman, M. Rhodes, D. Rodgers, and D. Vanous, Mariner 9 Michelson interferometer, Appl. Opt., 11, 2625, $1972 b$.

Hanel, R. A., V. G. Kunde, B. J. Conrath, and J. C. Pearl, Mariner 9 interferometer spectrometer (IRIS) reduced data records documentation, report, Natl. Space Sci. Data Cent., Washington, D. C., 1973.

Herkenhoff, K. E., and B. C. Murray, Color and albedo of the south polar layered deposits on Mars, J. Geophys. Res., this issue.

Herkenhoff, K. E., L. A. Soderblom, B. C. Murray, and G. E. Danielson, Mariner 9 television calibration-Revisited, Icarus, $75,133,1988$.

Hunt, G. E., On the infrared radiative properties of $\mathrm{CO}_{2}$ ice clouds: Applications to Mars, Geophys. Res. Lett., 7, 481, 1980.

Jakosky, B. M., and E. S. Barker, Comparison of ground-based and Viking orbiter measurements of Martian water vapor: Variability of the seasonal cycle, Icarus, 57, 322, 1984.

James, P. B., G. Briggs, J. Barnes, and A. Spruck, Seasonal recession of Mars' south polar cap as seen by Viking, J. Geophys. Res., 84, 2889, 1979.

Kahn, R., The evolution of $\mathrm{CO}_{2}$ on Mars, Icarus, 62, 175, 1985.

Kieffer, H. H., Mars south polar spring and summer temperatures: A residual $\mathrm{CO}_{2}$ frost, J. Geophys. Res., 84, 8263, 1979.

Kieffer, H. H., S. C. Chase, T. Z. Martin, E. D. Miner, and F. D. Palluconi, Martian north pole summer temperatures: Dirty water ice, Science, 194, 1341, 1976a.

Kieffer, H. H., S. C. Chase, E. D. Miner, F. D. Palluconi, G. Münch, G. Neugebauer, and T. Z. Martin, Infrared thermal mapping of the Martian surface and atmosphere. First results, Science, 193, 780, $1976 b$.

Kieffer, H. H., T. Z. Martin, A. R. Peterfreund, B. M. Jakosky, E. D. Miner, and F. D. Palluconi, Thermal and albedo mapping of Mars during the Viking primary mission, J. Geophys. Res., 82, 4249, 1977. 
Leighton, R. R., and B. C. Murray, Behavior of $\mathrm{CO}_{2}$ and other volatiles on Mars, Science, 153, 136, 1966

McCord, T. B., and J. A. Westphal, Mars: Narrow-band photometry, from 0.3 to 2.5 microns, of surface regions during the 1969 apparition, Astrophys. J., 168, 141, 1971.

McElroy, M. B., Y. L. Yung, and A. O. Nier, Isotopic composition of nitrogen: Implications for the past history of Mars' atmosphere, Science, 194, 70, 1976.

Murray, B. C., and M. C. Malin, Polar volatiles on Mars-Theory versus observations, Science, 182, 437, 1973.

Murray, B. C., L. A. Soderblom, J. A. Cutts, R. P. Sharp, D. J. Milton, and R. B. Leighton, Geological framework of the south polar region of Mars, Icarus, 17, 328, 1972.

Paige, D. A., The annual heat balance of the Martian polar caps from Viking observations, Ph.D. thesis, Calif. Inst. of Technol., Pasadena, 1985.

Paige, D. A., An analysis of IRTM observations of the Martian polar regions during the polar night seasons, J. Geophys. Res., in press, 1989.

Paige, D. A., and A. P. Ingersoll, Annual heat balance of Martian polar caps: Viking observations, Science, 228, 1160, 1985.

Pang, K., and C. W. Hord, Mariner 9 Ultraviolet Spectrometer Experiment: 1971 Mars' dust storm, Icarus, 18, 481, 1973.

Pollack, J. B., Climatic change on the terrestrial planets, Icarus, 37, $479,1979$.

Pollack, J. B., Properties of dust in the Martian atmosphere and its effect on temperature structure, Adv. Space Res., 2, 45, 1982.

Pollack, J. B., D. S. Colburn, F. M. Flasar, R. Kahn, C. E.
Carlston, and D. Pidek, Properties and effects of dust particles suspended in the Martian atmosphere, J. Geophys. Res., 84, 2929-????, 1979.

Seidman, J. B., W. B. Green, P. L. Jepsen, R. M. Ruiz, and T. E. Thorpe, A user's guide to the Mariner 9 television reduced data record, Tech. Memo. 33-628, Jet Propul. Lab., Pasadena, Calif., 1973.

Thorpe, T. E., A history of Mars atmospheric opacity in the southern hemisphere during the Viking extended mission, $J$. Geophys. Res., 84, 6663, 1979.

Toon, O. B., J. B. Pollack, W. R. Ward, J. A. Burns, and K. Bilski, The astronomical theory of climatic change on Mars, Icarus, 44, $552,1980$.

Ward, W. R., B. C. Murray, and M. C. Malin, Climatic variations on Mars, 2, Evolution of carbon dioxide atmosphere and polar caps, J. Geophys. Res., 79, 3387, 1974.

K. E. Herkenhoff and B. C. Murray, Division of Geological and Planetary Sciences, California Institute of Technology, Pasadena, CA 91125 .

D. A. Paige, Department of Earth and Space Sciences, University of California, Los Angeles, CA 90024.

(Received September 16, 1988; revised June 15,1989 ; accepted June 19, 1989.) 